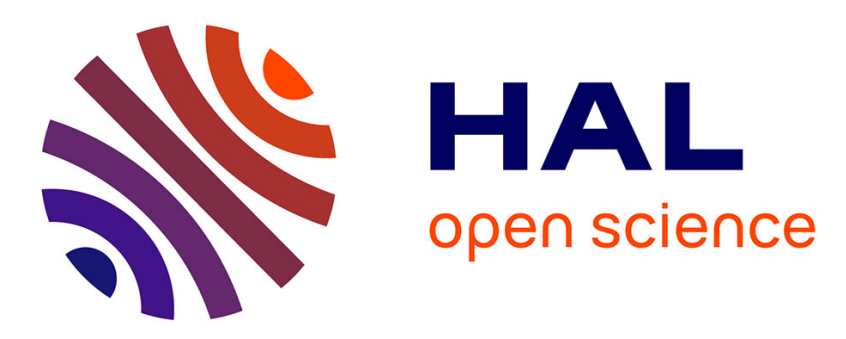

\title{
On the Indispensable Premises of the Indispensability Argument
}

\author{
Andrea Sereni, Marco Panza
}

\section{To cite this version:}

Andrea Sereni, Marco Panza. On the Indispensable Premises of the Indispensability Argument. Gabriele Lolli, Marco Panza, Giorgio Venturi. Philosophy of Mathematics; from Logic to Practice - Italian Studies in the Philosophy of Mathematics, 208, Springer, pp.241-276, 2015, Boston Studies in the Philosophy and History of Science, 978-3-319-10433-1, 978-3-319-10434-8. 10.1007/978-3-31910434-8_13. halshs-01095980

\section{HAL Id: halshs-01095980 https://shs.hal.science/halshs-01095980}

Submitted on 5 Jan 2015

HAL is a multi-disciplinary open access archive for the deposit and dissemination of scientific research documents, whether they are published or not. The documents may come from teaching and research institutions in France or abroad, or from public or private research centers.
L'archive ouverte pluridisciplinaire HAL, est destinée au dépôt et à la diffusion de documents scientifiques de niveau recherche, publiés ou non, émanant des établissements d'enseignement et de recherche français ou étrangers, des laboratoires publics ou privés. 


\title{
On the Indispensable Premises of the Indispensability Argument
}

\author{
Marco Panza (IHPST, CNRS Paris1), marco.panza@univ-paris1.fr \\ Andrea Sereni (IUSS, Pavia / San Raffaele University, Milan), andrea.sereni@iusspavia.it
}

\begin{abstract}
We identify four different minimal versions of the indispensability argument, falling under four difference varieties: an epistemic argument for semantic realism, an epistemic argument for platonism, and a non-epistemic version of both. We argue that most current formulations of the argument can be reconstructed by building upon the suggested minimal versions. Part of our discussion relies on a clarification of the notion of (in)dispensability as relational in character. We then present some substantive consequences of our inquiry for the philosophical significance of the indispensability argument, the most relevant of which being that both naturalism and confirmational holism can be dispensed with, contrary to what is held by many.
\end{abstract}

\section{Introduction}

The recent debate on the indispensability argument (henceforth, IA) in the philosophy of mathematics features an impressive number of versions of the argument, all somehow pointing back to what is referred to as "the Quine-Putnam indispensability argument", that is to Quine's several scattered remarks on the subject and to Putnam's [1971] first proper formulation of a version of IA. It is thus legitimate to wonder whether all (or, at least, most of) the versions available on the market can be really traced back to some minimal shared structure.

After rehearsing the most common stances towards IA, the main aim of this paper is to offer four minimal versions of IA, minimal in so far as they feature, according to classifications that will be explained below, the fewest or least controversial premises needed to gain the desired conclusion(s). We will submit that different formulations of IA on the market, related to the common stances to be discussed, could be retrieved from the 
minimal arguments to be offered ${ }^{1}$.

Despite its methodological character, the following inquiry will have as a substantive conclusion that in order to obtain the desired conclusions some commonly required assumptions - namely, confirmational holism and naturalism - will prove dispensable.

Since it is not our intention in this occasion to take a stance in the debate on indispensability, many of the criticisms or defences of IA will not be discussed.

The structure of the paper is as follows. $\S 2$ introduces the issue by reference to the debate by considering some representative versions of the argument. § 3 offers a taxonomy of four minimal versions of IA. $\S 4$ focuses on the notion of (in)dispensability. $\S 5$ considers in details which assumptions and notions are really needed if one wishes to endorse the minimal arguments. $\S 6$ indicates how the representative versions considered in $\S 2$ can be retrieved from the minimal arguments. $\S 7$ offers concluding remarks on the bearing of the present inquiries for the philosophical significance of IA.

\section{The Indispensability Argument: four common stances}

A few expository remarks will help us to single out four common stances concerning the structure and significance of IA that we take as representative of the ongoing debate.

Putnam [1971]'s well-known passage is commonly assumed as the reference formulation:

So far I have been developing an argument for realism roughly along the following lines: quantification over mathematical entities is indispensable for science, both formal and physical, therefore we should accept such quantification; but this commits us to accepting the existence of the mathematical entities in question. This type of argument stems, of course, from Quine... [Putnam 1971, p. 347].

Putnam wavers, at different places, between considering the conclusion of the

${ }^{1}$ This paper builds on the analysis of indispensability arguments presented in Panza, Sereni [2013], chs. 6-7; some of its conclusions, together with the four versions of the minimal indispensability argument discussed in $\S 3$, have thus been anticipated in that work. 
argument to be a form of platonism, or rather a conclusion in favour of mathematical realism ${ }^{2}$. For our present purpose, it suffices that the two theses are acknowledged as distinct and both plausible: by platonism we mean, the thesis that there exist objects of a certain sort, namely such that our current mathematical theories can be taken to be about them, in short that there exist mathematical objects ${ }^{3}$; by mathematical realism we mean a particular form of semantic realism, i.e. the thesis that the statements encompassed by our current mathematical theories, or better its theorems or consequences, are true (without specific commitment to what makes them true $)^{4}$.

Puntnam's own views apart, his quotation above is commonly seen as a paradigmatic example of an argument for platonism. Prima facie, the Putnam's version of the argument appeals only two notions, indispensability and quantification. However, many believe that beside these notions, IA relies on some additional theses of Quinean provenance: confirmational holism and naturalism. The most debated formulation of IA that is faithful to this conception has been advanced by Mark Colyvan's:

i) We ought to have ontological commitment to all and only those entities that are indispensable to our best scientific theories;

ii) Mathematical entities are indispensable to our best scientific theories;

iii) We ought to have ontological commitment to mathematical entities

${ }^{2}$ Cf. Liggins [2008] for a reconstruction.

${ }^{3}$ If fact, we believe that other possible (and possibly more plausible) forms of platonism could be fashioned, and that the thesis just mentioned should then be more correctly called 'ontological platonism'. However, insofar as it is not part of our present aims to argue for such distinction, we avoid this specification and call it 'platonism' tout court. Nothing in this thesis mandates that mathematical objects are abstract, and indeed, though this is generally (or at least, often) admitted, IA can support the thesis without going into details about the nature of mathematical objects.

4 Semantic realism as conceived here is distinct from what Michael Dummett called 'realism' (see e.g. Dummett [1978]): the latter is a thesis about statements possessing an objective, mind-independent truthvalue, whereas the former is the claim that the relevant statements are true (possibly in a mind-independent way, but not necessarily).

${ }^{5}$ Colyvan [2001, p. 11]. Cf. also Resnik [1995, p. 430]. 
According to Colyvan, "the crucial first premise follows from the doctrines of naturalism and holism"6. Naturalism would be required in order to justify the onlydirection of the implication, which, as Colyvan himself acknowledge ${ }^{7}$, is, in fact, redundant for drawing the conclusion, and confirmational holism to justify the alldirection. Whether this is so hinges on how the notions involved are defined.

So far, we are confronted with representatives of two different stances on IA. On the one hand, Putnam is concerned with logico-syntactical features of scientific theories and their expressive power: what is at stake is whether some particular vocabulary is necessary in order to state some given scientific laws ${ }^{8}$. On the other hand, Colyvan's formulation widens the scope by taking into account general concerns in the philosophy of science, especially as regards the relation between philosophy and science and the way in which empirical evidence is meant to confirm scientific theories.

There is yet a third stance on IA. Hartry Field first suggested that a particular version of IA involves indispensability "for explanations" [1989, p. 14]: if we have a theory that we take to be our best explanation of a given set of (arguably empirical) phenomena, and this theory includes some statements to the extent that certain (sorts of) objects exist, then we "have a strong reason to believe" (ibid., p. 15) in the truth of the statements in question, and consequently (pending a clarification of the ontological import of existential statements) in the existence of the relevant (sorts of) objects. This requires that inference to the best explanation (IBE) is considered a reliable principle. This third stance on IA thus equates (faithful to some of Quine's remarks, as well as to Putnam's overall picture) arguments for mathematical (ontological) realism and arguments for scientific realism about unobservable entities, where IBE is often appealed to. As a result of the recent vast debate on explanation, and mathematical explanation in particular ${ }^{9}$, Alan

${ }^{6}$ Colyvan [2001, p. 12].

${ }^{7}$ Cf. Colyvan [2001, p. 12]: “[...] I should point out that the first premise, as I've stated it, is a little stronger than required. In order to gain the given conclusion all that is really required in the first premise is the 'all,' not the 'all and only, ' I include the 'all and only, ' however, for the sake of completeness and also to help highlight the important role naturalism plays in questions about ontology, since it is naturalism that counsels us to look to science and nowhere else for answers to ontological questions".

${ }^{8} \mathrm{Cf} . \S \S \mathrm{V}$ to VIII of Putnam [1971].

${ }^{9}$ Cf. Hafner, Mancosu [2005], Baker [2005, 2009], Mancosu [2008] 
Baker [2009, p. 613] has claimed that "for the purposes of establishing platonism [...] it needs to be shown that reference to mathematical objects sometimes plays an explanatory role in science". He has thus offered the following "Enhanced Indispensability Argument" (ibid.):

i) We ought rationally to believe in the existence of any entity which plays an indispensable explanatory role in our best scientific theories;

ii) Mathematical objects play an indispensable explanatory role in science;

iii) Hence, we ought rationally to believe in the existence of to mathematical objects.

Finally, we have a fourth stance, represented by arguments that build on pragmatic considerations, or generally considerations concerned with scientific practice and its needs. The most representative argument in this case has been presented by Resnik [1995, pp. 169-171; 1997, pp. 46-7] ${ }^{10}$ :

i) In stating its laws and conducting its derivations science assumes the existence of many mathematical objects and the truth of much mathematics.

ii) These assumptions are indispensable to the pursuit of science; moreover, many of the important conclusions drawn from and within science could not be drawn without taking mathematical claims to be true.

iii) So we are justified in drawing conclusions from and within science only if we are justified in taking the mathematics used in science to be true.

iv) We are justified in doing science.

v) The only way we know of doing science involves drawing conclusions from and within it.

vi) So, we are justified in taking that mathematics to be true.

\footnotetext{
${ }^{10}$ The argument is presented in slightly different terms in the two occasions. We are here using the one in Resnik [1995].
} 
(vii) So, mathematics is true.

Setting apart any consideration about the validity of this version of IA, let us just notice that it differs from the previous versions to the extent that, as Resnik himself claims, it does not depend on the claim that "the evidence for science (one body of statements) is also evidence for its mathematical components (another body of statements)", but merely requires that "the justification for doing science (one act) also justifies our accepting as true such mathematics as science uses (another act)" ${ }^{11}$.

More recently, Azzouni [2009] has offered a reading of IA that is also based, though in rather different terms, on pragmatic considerations. More specifically, in a vein similar to ours (cf. footnote 17 below), Azzouni offers the following enthymematic "blueprint" for IA:

Premise: Certain statements that quantify over mathematical entities are indispensable to science.

Conclusion: Those statements are true.

as underlying a family of arguments usually referred to as 'Quine-Putnam indispensability argument'. He then proposes to expand on this blueprint in order to offer what he labels the 'Assertoric-use QP', a version of IA based on the fact that what he calls the 'assertoric use' of mathematical statements is indispensable to science, and that this use commits speakers to the truth of the statements in question. We will consider Azzouni's proposal, together with what we take to be a plausible reconstruction of his Assertoric-use QP, in more details below in $\S 6$.

For the time being, it is important to acknowledge that four major stances emerge when looking at the different versions of IA actually on the market, hinging respectively on logico-syntactic considerations related to expressive power (as in Putnam), on general views on science and confirmation (as in Colyvan), on the notion of explanation (as in Baker), and on features of scientific practice (as in Resnik or Azzouni). It is relevant to emphasize this point, since if minimal versions of IA are to be offered, they should at

\footnotetext{
${ }^{11}$ Resnik [1995, p. 171].
} 
least to be compatible with these common stances. It is not our intention to offer a minimal formulation corresponding to each of these representative arguments. However, we will discuss to which extent and how it is possible, from the minimal versions to be offered, to retrieve something very close to them, or at least as close as to fit with the same stances.

\section{The Minimal Indispensability Argument(s)}

Since our aim is to establish, with respect to available versions of IA, what a minimal argument needs retain, and what it can let go, we better start by considering the features of Colyvan's argument, which appears to be the most theoretically loaded version among the ones reviewed above. Here are some of its essential features. Firstly and obviously, it appeals to some notion of indispensability. Secondly, it is an argument for platonism, and not just for semantic realism. Thirdly, it is an argument stated in epistemic terms on two scores: on the one side, its premises and conclusions deal with what we "ought to" believe, or what entities we "ought to" be ontologically committed to; on the other side, it deals with the notion of justification, since 'best', in "best scientific theories", should be understood as "best justified"12. Fourthly, it appeals to the notion of ontological commitment; here, as in most cases, Quine's criterion ([QC]) is the relevant one ${ }^{13}$. Fifthly, it is claimed to rely, for the justification of its first premise, on naturalism, and, sixthly and finally, on confirmational holism.

Are all of these features essential in order to obtain a version of IA? Obviously, any

${ }^{12}$ Though Colyvan does not explicitly equate 'best' with 'best justified', the list of scientific virtues he considers in Colyvan [2001, pp. 78-9] for a scientific theory to count as good-among which are empirical adequacy, consistency, simplicity and parsimony, unificatory and explanatory power, boldness and fruitfulness, and formal elegance_-makes clear that he (like other supporters of IA) has much more in mind than simply currently accepted theories. Notice, in passing, that the 'ought to', as opposed to the 'best justified', has both a permissive and a prescriptive component. We will not put much weight on the latter.

${ }^{13}$ Cf. Colyvan [2001, pp. 22-24] for some qualifications. Briefly, [QC] states that the ontological commitment of a theory $\mathrm{T}$ is given by the objects that must be counted in the range of the objectual quantifiers in the existential theorems of (the canonical reformulation of) T. [QC] plays in Colyvan's argument the same role that quantification plays in Putnam's argument. Cf. Quine [1948]. 
such version needs retain the first feature: it requires appeal to some notion of indispensability. But things are different with the other features.

Clearly, some criterion is needed for selecting those scientific theories to which the argument is meant to apply. One can, however, either appeal here to epistemic notions or to non-epistemic notions, such as truth. We thus get a first broad distinction between arguments stated in epistemic or in non-epistemic terms.

Further, as already remarked, IA can be an argument for mathematical realism, rather than platonism, and we need to keep the two possibilities apart.

We thus end up with four possible varieties of IA: as an epistemic argument for mathematical realism, as an epistemic argument for platonism, and, respectively, as a non-epistemic variety of each.

Let us begin with epistemic versions of IA for mathematical realism. As regards the selection criterion for theories, the most natural choice is for a criterion based on justification $^{14}$. Justification, however, comes in many forms. For the time being, our appeal to it will be independent of any particular theory of justification. We could even not assume that justification for a theory is justification in believing the theory true: having justification for a scientific theory could be understood as simply having reasons, even only pragmatic ones, for adopting a scientific theory in ordinary scientific practice - e.g. because it is instrumentally helpful, or predictively accurate, or the like. This would lead to an argument along the following lines: we have a justification for some scientific theories; among them, some are such that some mathematical theories are indispensable to them; we have a justification for these scientific theories only if we a have a justification for the mathematical theories that are indispensable to them; therefore, we have a justification for the mathematical theories indispensable to these scientific theories.

No mention of truth is made here. This is prima facie consistent with Colyvan's argument, where no mention of truth is made either. Admittedly, however, in the debate

\footnotetext{
${ }^{14}$ Notice that a weaker notion, like that of acceptance of a scientific theory, modelled e.g. on the lines suggested by Van Fraassen [1980], will not be strong enough to deliver the required mathematical realist or platonist conclusion. We will consider later the possibility of appealing merely to the notion of confirmation rather than that of justification.
} 
on IA - and in Colyvan's discussion too-justification is understood as justification for the truth of a theory. We can, then, specify the argument accordingly, and get the following version of IA:

\section{Realism, epistemic [RE]}

i) We are justified in believing some scientific theories to be true;

[We are justified in believing $\mathrm{T}$ is true]

ii) Among them, some are such that some mathematical theories are indispensable to them;

[M is indispensable to T]

iii) We are justified in believing true these scientific theories only if we are justified in believing true the mathematical theories that are indispensable to them;

[We are justified in believing $\mathrm{T}$ true only if we are justified in believing $\mathrm{M}$ true]

\section{$[\mathrm{RE}]$}

iv) We are justified in believing true the mathematical theories indispensable to these scientific theories.

[We are justified in believing $\mathrm{M}$ true]

In what follows, we will take $[\mathrm{RE}]$ as the reference formulation for a minimal epistemic version of IA for semantic realism. [RE] is nothing but a specification of the more general argument sketched above, in which justification need not be justification for truth. Should we rest content with that more general argument, however, we could hardly obtain an argument for mathematical realism, for we would lack, unless further premises are added, any link between the justification of a theory and its truth (this is why we do not consider that version of the argument as one of our minimal versions of IA).

Since no mention of mathematical objects is made in [RE], [QC] - as any other alternative criterion-is not needed in the formulation nor in the justification of its premises. $[\mathrm{RE}]$ is neutral as to whether it is the existence of mathematical objects that makes the relevant mathematical theories true. [RE] would be a desirable version of IA for all those who believe in the objectivity and truth of mathematics, but would not by this fact alone qualify themselves as platonists ${ }^{15}$.

15 Putnam's [1967] equivalent descriptions, or Hellman's [1989] modal structuralism are two wellknown candidates. [RE] seems also to respect the basic ideas underlying the criticisms that Pincock [2004], 
Despite this, from [RE], an epistemic version of IA for platonism can be easily obtained by adding a premise introducing some appropriate criterion of ontological commitment:

\section{Platonism, epistemic [PE]}

i) We are justified in believing some scientific theories to be true;

[We are justified in believing $\mathrm{T}$ is true]

ii) Among them, some are such that some mathematical theories are indispensable to them;

[M is indispensable to $\mathrm{T}$ ]

iii) We are justified in believing true these scientific theories only if we are justified in believing true the mathematical theories that are indispensable to them;

[We are justified in believing $\mathrm{T}$ true only if we are justified in believing $\mathrm{M}$ true]

iv) We are justified in believing true a mathematical theory only if we are justified in believing the objects it is about to exist;

[We are justified in believing $\mathrm{M}$ true only if we are justified in believing the objects it is about to exist]

$[\mathrm{PE}]$

v) We are justified in believing the objects which the indispensable mathematical theories are about to exist

[We are justified in believing the objects $\mathrm{M}$ is about to exist]

Indispensability arguments are most of the time cast in epistemic terms. As Colyvan himself stresses, this epistemic character is due to a conception of ontology as a prescriptive and normative discipline: it tells us what we ought to believe to exist, or, in other terms, what we are justified in believing to exist ${ }^{16}$. However, one might rather conceive of ontology as a descriptive discipline, and ask for arguments whose conclusions tell us that certain (sorts of) objects do exist, not just that we are justified in believing them to exist. Let us then formulate the arguments in a non-epistemic fashion:

Realism, non-epistemic [RnE]

Azzouni [2004] and Paseau [2007] move against the standard platonist versions of IA.

${ }^{16}$ Cf. Colyvan [2001], p.11. Cf. also fn. 8 above. 
i) There are true scientific theories;

[T is true]

ii) Among them, some are such that some mathematical theories are indispensable to them;

[M is indispensable to T]

iii) These scientific theories are true only if their indispensable mathematical theories are themselves true;

[ $\mathrm{T}$ is true only if $\mathrm{M}$ is true]

$[\mathrm{RnE}]$

iv) The mathematical theories indispensable to these scientific theories are true ${ }^{17}$

[M is true]

\section{Platonism, non-epistemic [PnE]}

i) There are true scientific theories;

[T is true]

ii) Among them, some are such that some mathematical theories are indispensable to them;

[M is indispensable to T]

iii) These scientific theories are true only if their indispensable mathematical theories are themselves true;

[ $\mathrm{T}$ is true only if $\mathrm{M}$ is true]

iv) A mathematical theory is true only if the objects it is about exist;

[M is true only if the objects $\mathrm{M}$ is about exist]

$[\mathrm{PnE}]$

v) The objects which the indispensable mathematical theories are about exist

[The objects $M$ is about exist]

All these four minimal versions of IA are schematic, in more than one sense. First of all, ' $\mathrm{T}$ ' and ' $\mathrm{M}$ ', in the bracketed version of each premise, can be substituted, respectively, with particular scientific and mathematical theories. Furthermore, the meaning of 'indispensable', 'justification', 'true' in all four arguments can be specified in different ways, so as to get strictly different arguments according to which specification is chosen.

\footnotetext{
${ }^{17}$ Those who believe the first premise to be too harsh can still accept a weaker formulation in which that premise is discharged and the conclusion is conditional in form, i.e. 'If there are true theories, then ...'.
} 
What is relevant is that the notions of justification and truth, however specified, must be such that justification in believing a theory true, and truth itself, are preserved under indispensability, however the latter is specified on its turn. In arguments for platonism, moreover, premise (iv) can be further qualified according to any preferred specification of the intuitive notion of aboutness (in Quinean terms, that premise would be specified, according to $[\mathrm{QC}]$, by reference to quantifiers and their domain $)^{18}$.

Prima facie, no such theses as naturalism, confirmational holism (or other) seem to be explicitly involved in the minimal arguments. But it remains open whether these (or other) theses are required, even as background assumptions, for the soundness of these arguments; this must be discussed in more details, especially if the relations between the minimal versions and the four representative versions of IA presented in the $\S 2$ must be spelled out. We will first pause to discuss the notion of (in)dispensability in the next section, and then consider which assumptions and notions are really involved in the minimal arguments. The following discussion concerning both (in)dispensability and other relevant notions will also help clarifying how several versions of IA can be retrieved from our suggested minimal versions (cf. §6 below).

\section{The relational character of (in)dispensability}

Despite its obvious relevance for IA, the notion of (in)dispensability has undergone little specific analysis in the debate. What is exactly taken to be indispensable? And to what? And what does it mean to be indispensable?

As regards the first question, different aspects or ingredients of mathematics can and are taken into account in formulations of IA: the quantification over mathematical "entities" or (putative) "objects" (like in Putnam [1971]); mathematical entities or objects themselves, like in Colyvan [2011], p. 11, or Baker [2005] or many others; the apparent

\footnotetext{
${ }^{18}$ Also Azzouni's blueprint reported in $§ 2$ above could be thought to be schematic. However, this is so in a different sense. Whereas our arguments are schematic in that they can be turned into strictly different versions of IA by further specifying some of the notions involved, Azzouni's blueprint is rather a matrix from which explicit and logically valid versions of IA can be obtained through the addition of other assumptions.
} 
reference to such entities or objects, like in Colyvan [2011], p. 7; the assumption of the truth of some mathematical statements (namely, statements involving mathematical vocabulary), like in Resnik [1995], pp. 169-171; [1997], pp. 46-48; mathematical vocabulary (which we take to be what is often implicitly intended when authors use 'apparent reference', like in Colyvan [2011], p. 16; some appropriate use of mathematical statements, like in Azzouni [2009]; or finally, mathematical theories.

It is possible to maintain that there are significant differences stemming from these allegedly alternative choices. Those who believe this should also consider minimal schematic versions of $\mathrm{AI}$ in which it is not specified what is taken to be indispensable. We will not dwell here on this matter, as well as on other possible parameters that fully schematic version of IA can involve (for instance, parameters specifying whether indispensability is constrained by certain goals we want our scientific theories to achieve), since we consider this at length elsewhere (cf. Panza, Sereni [forthcoming]). Here, we rather assume that there is a common idea underlying all the mentioned options regarding what is to be taken as indispensable, namely that the relevant scientific theories have an essential recourse to a vocabulary fixed by some mathematical theories, and then to the notions that this vocabulary is supposed to convey. As far as what is taken to be indispensable is some appropriate use of mathematical statements, we take it that what is relevant is that of the statements of a mathematical theory, or statements involving the mathematical vocabulary fixed by this theory, it is possible to make this appropriate use -while (appropriately) using (the statements of) a scientific theory. So also this option seems to reduce, with this proviso, to the option according to which it is the use of theories to be indispensable (to other theories; see below the answer to the second question).$^{19}$ Moreover, it seems to us that by literally accepting the option that what is indispensable are mathematical entities or objects themselves, one is open to an obvious risk of circularity (unless one is ready to concede that these entities or objects could be indispensable as such without existing). Here, thus, we will rest content with taking

\footnotetext{
${ }^{19}$ A different issue is whether an argument based on the indispensability of the use of theories can be retrieved from arguments based on the indispensability of theories tout court: we will come back to this in $\S 6$.
} 
mathematical theories, as what is said to be indispensable in IA, though leaving open the possibility of understanding this, when more details are given, in different ways.

Parallel considerations also apply to the second question. We will thus rest content with taking other theories, typically scientific ones, to be that for which mathematical theories are said to be indispensable in IA, although we leave open, again, the possibility of understanding this, when more details are given, in different ways ${ }^{20}$.

The third question seems to us much more relevant. Let us focus on that, then. As will be clear, this will also help explain how some common versions of IA can be retrieved from the minimal versions through appropriate specifications of this notion.

What does it really mean that a theory is indispensable to another? Let $\mathrm{T}$ be a scientific theory, and $\mathrm{m}$ a mathematical theory employed in the formulation of $\mathrm{T}$. Let us call, for short, a statement employing the vocabulary of a theory $\mathrm{M}$ an 'M-loaded statement'. It seems to us obvious to take $\mathrm{M}$ to be indispensable to $\mathrm{T}$ if it is not possible to obtain from $\mathrm{T}$ a theory T', equivalent to $\mathrm{T}$ according to some specified equivalence relation, in which $\mathrm{M}$ loaded statements do not occur. But, then, given any version of IA, in order to specify the indispensability condition involved in it one has to choose the appropriate equivalence relation according to which T' is to be taken as equivalent to T. In most cases, it seems to be tacitly admitted that the relevant equivalence relation is such that if $\mathrm{T}$ ' is equivalent to $\mathrm{T}$ according to it, then T' preserves the descriptive and predictive power of $\mathrm{T}$. This suggests taking this relation to be something like the relation of having the same empirical adequacy, or that of having the same observational consequences. Still, other choices could be pertinent.

Making this choice will not be enough, however, since it is also important to make sure that the equivalence between $T$ and $T$ ' is not obtained by merely formal gerrymandering. This requirement captures Field's suggestion that T' has to be "reasonably attractive" [1980, p. 8], or Colyvan's suggestion that it must be "preferable" to T [2001, p. 77]. Craig's Theorem is, for example, a well-known example of a purely

${ }^{20}$ Whether we should consider a mathematical theory $\mathrm{M}$ indispensable to a theory $\mathrm{T}$ when only some parts of $\mathrm{M}$ are as a matter of fact used for the formulation of $\mathrm{T}$ depends, among other things, on whether the employed part of $\mathrm{M}$ is such that it can be considered an independent (sub-)theory of $\mathrm{M}$. This is what Peressini [1997] labels 'the problem of the unit of indispensability'. 
formal method for obtaining from any (recursively enumerable theory) theory $\mathrm{T}$ involving M-loaded statements a (recursively axiomatizable theory) theory T' that involves no such statement and has the same observational content ${ }^{21}$.

Attractiveness and preferability are aim-specific notions, to be decided on broadly scientific criteria case by case. We can express this point in full generality by saying that T' has to be equally or even more scientifically virtuous than $\mathrm{T}$, where the appropriate criterion of virtuosity will be fixed considering common scientific virtues, according to our specific purpose.

We can thus offer the following general clarification of the notion of (in)dispensability:

\section{[IND] (In)dispensability}

A theory $\mathrm{M}$ is dispensable from a given scientific theory $\mathrm{T}$ if and only if there is a scientific theory T' that does not include M-loaded statements and that:

a) is $\varepsilon$-equivalent to T, where $\varepsilon$ is an appropriate equivalence relation;

$b$ ) is equally or more virtuous than $\mathrm{T}$ according to an appropriate criterion of virtuosity $\alpha$.

If $\mathrm{T}$ includes $\mathrm{M}$-loaded statements, and there is no scientific theory $\mathrm{T}$ ' satisfying the above conditions, then $\mathrm{M}$ is indispensable to $\mathrm{T}$.

A noteworthy consequence of this definition is that common talk of (in)dispensability is partly inaccurate. No theory is (in)dispensable tout court to another theory, but only relative to a certain equivalence relation. We should better speak of $\varepsilon$ - $\alpha$-(in)dispensability, rather than (in)dispensability simpliciter. (In)dispensability is an essentially relational

\footnotetext{
${ }^{21}$ According to Craig's Theorem [Craig 1956], given a recursively enumerable theory $\mathrm{T}$, and a partition of its vocabulary into an observational one, $o$, and a theoretical one, $t$, then there exist a recursively axiomatizable theory T', whose only non-logical vocabulary is $o$, comprising all and only the consequences of T expressible in $o$. Craig himself warned against the philosophical import of his result, claiming that the theorems of $\mathrm{T}$ " obtained by his re-axiomatization method are not "psychologically or mathematically [...] perspicuous" than those of T, this being "basically due to the mechanical and artificial way in which they are produced" (p. 49).
} 
notion $^{22}$.

According to which equivalence relation is selected, IA can have different philosophical significance. Some minimal notion of indispensability can be thought of, if the equivalence relation $\varepsilon$ is chosen on logico-syntactical grounds (e.g. if it is taken to be the relation of having the same expressive power, i.e. of including either the same theorems or definitional paraphrases of them). But more demanding notions can be thought of. For instance, one could suggest using such an the equivalence relation like that of having the same explanatory power, or cognate ones. Should theorists such as Field and Baker, building on the third of the four stances mentioned in $\S 2$, be willing to endorse any of the minimal IA suggested above, they could easily obtain a specification of them based on the notion of explanatory power: once $\varepsilon$ is appropriately specified in this way, it will straightforwardly follows that $\mathrm{M}$ is indispensable to $\mathrm{T}$ only it plays an indispensable explanatory role in $\mathrm{T}$. We will come back to this below ${ }^{23}$.

\section{What Does It Takes to Be an Indispensability Argument?}

${ }^{22}$ Colyvan's discussion of "the role of confirmation theory" in his [2001, pp. 78-81] hints to the relational character of the notion of preferability. We take our clarification of (in)dispensability to improve on that suggestion.

${ }^{23}$ As pointed out to us by an anonymous referee, our schematic definition of (in)dispensability assign no special role to the notion of applicability of a mathematical theory. It goes without saying that we acknowledge the greatest importance to the problem of the applicability of mathematics and to its role within the debate concerning IA, although it is impossible to discuss these issues here. We do believe, however, that, although the two notions will be certainly connected eventually, they can be beneficially treated separately at a general level of analysis as ours. Whether and how a particular conception of applicability affects a given version of IA - either by facilitating its conclusion, or by preventing it - is, indeed, something that we believe will have to be considered case by case, according to versions of the argument appropriately specified so to involve, for instance, one's preferred notion of applicability in the specification of either the equivalence relation $\varepsilon$ or the criterion of virtuosity $\alpha$. 
In this section we explore which assumptions or theoretical ingredients generally, beyond the notion of (in)dispensability, are required in order either to formulate or to endorse one of the minimal versions of IA presented above. We begin by considering the role of doctrines such as naturalism and confirmational holism. On a fairly common understanding - and in accordance with working definitions to be given below-these doctrines are only relevant for epistemic argument, being concerned as they are with the justification of scientific theories. Other assumptions will turn out as involved in nonepistemic arguments also.

\subsection{Confirmational holism and naturalism}

Nothing - and a fortiori naturalism and holism — is required, in [RE] or [PE], to justify an all-and-only-clause like that in Colyvan's argument, simply because there is no such clause to be justified at all. However, these doctrines may still be thought to be necessary conditions for justifying some of the premises of those arguments. A related concern is whether either doctrines might represent sufficient conditions.

Apart for a some aspect to be considered shortly, we will take for granted a general understanding of the notions involved (and of the vast debate concerning their proper characterization), and will merely state them in a convenient form for future reference, taking it that these formulations are those that philosophers concerned with IA have most commonly in mind:

[CH] Confirmational Holism: [Since the appreciation of empirical evidence is in no way a matter of comparing a single fact with a single hypothesis,] the confirmation of a single hypothesis or of a system of hypotheses comes together with (or entails) the confirmation of a larger net of hypotheses (possibly of the whole net of hypotheses that our knowledge consists in).

[NAT] Naturalism: [Since scientific theories are the only source of genuine knowledge,] we are justified in believing to be true only scientific theories, or 
other theories (or statements) whose truth follows from the truth of some scientific theories.

In what follows, we assume that it is legitimate to talk about the justification of mathematical and scientific theories independently of whether $[\mathrm{CH}]$ or [NAT] turn out to be necessary or unnecessary assumptions for the justification of any premise in the minimal arguments: [NAT], by itself, tells us only which sort of theories can be true, but is not taken as constitutive of the notion of justification; and whereas confirmation could be seen as constitutive of the justification of empirical theories, the way in which confirmation is accrued need not be such: even if confirmation is holistic, the claim that a scientific theory is justified does not presuppose by itself $[\mathrm{CH}]$.

If one wishes, $[\mathrm{CH}]$ and $[\mathrm{NAT}]$ could be specified further in order to have a distinctive focus on ontology, and would thus state, respectively, that the confirmation of a single hypothesis or of a system of hypotheses comes together with (or entails) the confirmation of the existence of all the entities that are quantified over in a larger net of hypotheses (possibly in the whole net of hypotheses that our knowledge consists in); and that we are justified in acknowledging the existence only of those entities that are quantified over in our scientific theories. In these particular formulations, naturalism and holism could be taken to be explicitly stated - not just posited as background assumptions - in the first premise of Colyvan's argument.

As stated, [NAT] entails the thesis that our scientific theories are our only source of genuine knowledge about the world. Many versions of naturalism are available, but in order to make it both plausible and relevant to IA, one should steer clear from at least two readings.

On the one reading, naturalism is the too strong thesis, almost indistinguishable from nominalism, that only non-abstract entities can be acknowledged to exist. Both what Colyvan [2001, ch. 3] calls 'Eleatic Principle', and the version of naturalism endorsed by e.g. Weir [2005] and Armstrong [1997, p. 5] are cases in point. We agree with Colyvan that if naturalism is involved in IA at all, it cannot be of this kind, since it stands in clear contradiction with the latter's conclusion.

On another reading, naturalism can be too weak to be relevant to IA. In discussing Quinean naturalism, Colyvan [2001, pp. 23-24] distinguishes two strands: the "No First 
Philosophy Thesis", being the (normative) thesis that in approaching "certain fundamental questions about our knowledge of the world" we should "look to science (and nowhere else) for the answers"; and the "Continuity Thesis", being the (descriptive) thesis that "philosophy is continuous with science and that together they aim to investigate and explain the world around us". Colyvan himself argues that these two theses are intimately related in a complex way. One thing, however, should be clear, beyond Quinean exegesis. If the Continuity Thesis is meant to claim that both science and philosophy, where this involves a priori methods of inquiry, are our only legitimate sources of knowledge about the world, the ensuing version of naturalism will not be suitable to the formulation of any empiricist argument. It can be suitable only in so far as one also adds that philosophy should abandon its traditional a priori methods and become a genuinely scientific (in the sense of empirical sciences) enterprise. But once this is added, empirical science and philosophy become utterly indistinguishable, and we come back to [NAT], with the only difference that in this new framework there is no philosophy left to be opposed to empirical sciences. The claim expressed in [NAT] seems to us to represent the most plausible reading of naturalism adequate for the formulation of an empiricist argument, as IA has been traditionally understood by Quine and his heirs. Notice, in passing, that we do believe that the 'only' in the formulation of [NAT] is crucial in order to distinguish naturalism from scientific realism; more on this below.

It now remains to be seen whether $[\mathrm{CH}]$ or $[\mathrm{NAT}]$ are either necessary or sufficient in order to justify any of the premises in $[\mathrm{RE}]$ and $[\mathrm{PE}]$. Premises (ii) of each argument, as well as [PE]'s premise (iv), are beyond any suspect of guilty here ${ }^{24}$. So we better concentrate on premises $(i)$ and (iii), common to both arguments. Premise $(i)$ is liable to the charge of surreptitiously appealing to naturalism, whereas premise (iii) is liable to the charge of surreptitiously appealing to holism. Let us consider the latter first.

\subsection{Can we dispense with confirmational holism?}

One could imagine a very simple way to settle the question whether endorsing holism is necessary for endorsing premise (iii) of [RE] or [PE]. It would consist in suggesting that the relevant form of holism we are to consider in connection with [RE] or [PE] is not, properly speaking, confirmational holism, but some sort of holism concerning justification, and that this form of holism just consists in the claim that justification of a

24 But, cf. footnote (30), below. 
theory $\mathrm{T}$ whatsoever transmits to any other theory indispensable to $\mathrm{T}$. In this case, the very claim that the justification of a scientific theory $\mathrm{s}$ transmits to a mathematical theory $\mathrm{M}$ indispensable to $\mathrm{S}$ would reduce to a mere instance of such a form of holism, and there would then be much room for claiming that endorsing it is necessary (beside being obviously sufficient) for endorsing this claim, and, then, premise (iii) of [RE] or [PE].

It seems to us, however, that such a form of holism would be not only different from that which is usually at stake when the relation between holism and IA are discussed, which is confirmational holism proper, that is, a form of holism specifically concerned with confirmation, rather than with justification in general, but that it would also be a quite Pickwickian form of holism, since it would merely require that justification transmits from a theory $\mathrm{T}$ to another theory so intimately connected to it as the indispensability of the latter for the former implies. Of course, in order to admit that this is so, one should maintain that indispensability is so specified as to warrant this transmission. Still, this is not the point here. What is relevant is rather that such a form of holism would restrict the transmission of justification from theory to theory to a case in which the relevant theories are related by a certain sort of intimate connection. But, if a proper form of holism of justification should be defended, it should rather consists in claiming that justification transmits much more widely, along a larger net of theories or hypotheses (possibly along the whole net of hypotheses that our knowledge consists in), without constraints such as that of indispensability.

The situation would be even more outlandish if it were argued that the relevant form of holism consists in the claim that justification of a scientific theory s transmits to a mathematical theory $\mathrm{M}$ indispensable to $\mathrm{S}$ (since it would be odd to consider that a sort of holism concerned with justification, in general, is restricted to the consideration of scientific and mathematical theories) or that confirmational holism, as such, consists in the claim that justification of a scientific theory $\mathrm{S}$ transmits to a mathematical theory $\mathrm{M}$ indispensable to s (since it would be odd to consider that confirmational holism generally concerns justification, rather than confirmation). In this latter case, premise (iii) of [RE] or $[\mathrm{PE}]$ would just be the same as confirmational holism and it would be beyond doubt that that endorsing the latter is necessary for endorsing the former. It seems however 
plain to us that confirmational holism is a different and wider thesis: not only it is concerned with confirmation rather than with justification, but also it is not merely limited to the transfer of confirmation from a scientific theory $\mathrm{s}$ to a mathematical theory $\mathrm{M}$ that is indispensable to $\mathrm{S}$.

All these considerations lead us to discard from the very beginning the simple possibilities just evoked, and to focus on confirmational holism proper, conceived as the very claim $[\mathrm{CH}]$.

A first, preliminary, difficulty is the following. Apparently, there is a striking asymmetry between the condition expressed in premise (iii) and that expressed in $[\mathrm{CH}]$ : the latter seems to express an inference from a part to the whole, whereas premise (iii) seems to express an inference from the whole to a part. We need therefore to understand how the two might be related in any way relevant (either sufficiently or necessarily) for lending support to premise (iii).

Under a quite weak reading if it, $[\mathrm{CH}]$ states that when a single hypothesis $h$ of a theory $\mathrm{s}$ is confirmed, the whole $\mathrm{s}$ is confirmed, which we express in symbols by: ' $\mathrm{C}(h)$ $\rightarrow \mathrm{C}(\mathrm{s})$ ', where ' $\mathrm{C}(x)$ ' stands for ' $x$ is confirmed'. If we admit that a mathematical theory $\mathrm{M}$ involved in a scientific theory s counts as a cluster of hypotheses of $\mathrm{s}$, one can replace here ' $\mathrm{C}(h)$ ' with ' $\mathrm{C}(\mathrm{M})$ ', so as to get the new implication ' $\mathrm{C}(\mathrm{M}) \rightarrow \mathrm{C}(\mathrm{s})$ '. It is however clear that this implication (be it admissible or not) is hardly useful in an argument whose purpose is that of building on considerations about some scientific theories in order to draw conclusions about some mathematical theories appropriately connected to the former. At most, the reciprocal implication ' $\mathrm{C}(\mathrm{s}) \rightarrow \mathrm{C}(\mathrm{M})$ ' could be relevant. But if a mathematical theory $\mathrm{M}$ involved in a scientific theory s counts as a cluster of hypotheses of $\mathrm{s}$, and we take confirmation to be cumulative, i.e. to be such that a conjunction of hypothesis (or of other items susceptible of confirmation) can only be confirmed by confirming all its conjuncts (which entails, of course, that confirmation is d'emblée also distributive: if a conjunction of hypothesis is confirmed all its conjuncts are so), this implication is trivial, since, whatever confirmation might come to in details, it is immediate to see that under this conception a theory cannot count as confirmed as a whole if some of its hypothesis are not so. Hence, in this case, arguing for this 
implication requires no appeal to any strong and/or controversial thesis, as confirmational holism appears to be.

Things change, however, if a mathematical theory $\mathrm{M}$ involved in a scientific theory $\mathrm{S}$ is rather taken to count as an auxiliary theory that s appeals to, without encompassing it, or if confirmation is not taken to be cumulative (and is, then, not warranted to be distributive, d'emblée), namely if it is admitted that a conjunction of hypothesis (or of other items susceptible of confirmation) can be directly confirmed as a whole (that is, without passing from a confirmation of all its conjuncts). Under both scenarios the implication ' $\mathrm{C}(\mathrm{s}) \rightarrow \mathrm{C}(\mathrm{M})$ ' becomes far from trivial: it asserts that confirming (in one way or another) a scientific theory $\mathrm{S}$ goes with (or is sufficient for) confirming either an auxiliary mathematical theory $\mathrm{M}$, which $\mathrm{s}$ appeals to it, but that is not included in $\mathrm{S}$ (under the former scenario), or a mathematical theory $M$ that $s$ encompasses, even if the confirmation of $\mathrm{M}$ is not, as such, involved in that of $\mathrm{s}$ (under the latter scenario). It seems to us that it is only under one of these scenarios that there is room for plausibly considering the possibility that $[\mathrm{RE}]$ and $[\mathrm{PE}]$ be somehow related with $[\mathrm{CH}]$, provided, of course, that a reading of $[\mathrm{CH}]$ be adopted, according to which this thesis entails that confirming a scientific theory s goes with (or is sufficient for) confirming an auxiliary mathematical theory $\mathrm{M}$, which $\mathrm{S}$ appeals to it, but that is not included in $\mathrm{S}$, or a mathematical theory $\mathrm{M}$ that $\mathrm{s}$ encompasses, within a framework in which confirmation is not taken to be cumulative.

It is not our purpose here to argue in favour either of one of these two possible scenarios, or of this reading of $[\mathrm{CH}]$. We merely suppose, for the sake of the argument, that both one of the former and the latter are admitted, while contending that if this is not so (that is, either both of the former or the latter are rejected), there is no plausible reason for connecting $[\mathrm{RE}]$ and $[\mathrm{PE}]$ with $[\mathrm{CH}]$. In other terms, we admit, for the sake of the argument, that $[\mathrm{CH}]$ entails ' $\mathrm{C}(\mathrm{s}) \rightarrow \mathrm{C}(\mathrm{M})$ ', provided that $\mathrm{s}$ and $\mathrm{M}$ are, respectively, a scientific and a mathematical theory, and that either s appeals to $\mathrm{M}$, without encompassing it, or $\mathrm{S}$ encompasses $\mathrm{M}$ but confirmation is not taken to be cumulative. For short, in what follow we shall call 'weak condition' (for reasons that will become clear below) the condition involved in this supposition, namely that either $\mathrm{S}$ appeals to $\mathrm{M}$, without 
encompassing it, or $\mathrm{S}$ encompasses $\mathrm{M}$, provided that confirmation is not taken to be cumulative.

Now, also admitting, under this same condition, that ' $\mathrm{C}(\mathrm{s}) \rightarrow \mathrm{C}(\mathrm{M})$ ' entails $[\mathrm{CH}]$ would be quite implausible, since, however it might be conceived, confirmational holism can certainly not be reduced to a thesis about the confirmational relation between scientific and mathematical theories under some condition whatsoever. The possibility still remains open, however, of admitting - for the sake of the argument, again, but without falling into an evident oddity - that, when confronted with a scientific theory $\mathrm{S}$ and a mathematical theory $\mathrm{M}$, under the weak condition, one has no other ground than $[\mathrm{CH}]$ for arguing that $\mathrm{C}(\mathrm{s}) \rightarrow \mathrm{C}(\mathrm{M})$. This is just what we admit. For the purpose of our following discussion, we can then suppose that, under the weak condition, endorsing $[\mathrm{CH}]$ is necessary for endorsing premise (iii) of $[\mathrm{RE}]$ and $[\mathrm{PE}]$ if endorsing the implication ' $\mathrm{C}(\mathrm{s}) \rightarrow \mathrm{C}(\mathrm{M})$ ' is necessary for this. As regards whether $[\mathrm{CH}]$ is sufficient for endorsing this same premise, things are much simpler. Since, if $[\mathrm{CH}]$ entails ${ }^{\prime} \mathrm{C}(\mathrm{s}) \rightarrow$ $\mathrm{C}(\mathrm{M})^{\prime}$ and ' $\mathrm{C}(\mathrm{s}) \rightarrow \mathrm{C}(\mathrm{M})$ ' entails this premises, then $[\mathrm{CH}]$ entails this premise. We can then limit our enquiry to this question: is endorsing the implication ' $\mathrm{C}(\mathrm{s}) \rightarrow \mathrm{C}(\mathrm{M})$ ', under the weak condition, necessary or sufficient for endorsing premise (iii) of $[\mathrm{RE}]$ and $[\mathrm{PE}]$ ?

Let us come back, then, to this premise. It states that justification to believe a mathematical theory $\mathrm{M}$, indispensable to a scientific theory $\mathrm{S}$, to be true is a necessary condition for having justification to believe that $\mathrm{S}$ is true. Let us call this the " $\mathrm{S}-\mathrm{M}$ justificatory connection under indispensability'. We can express it in symbols by: ' $\mathrm{IND}(\mathrm{M}, \mathrm{s}) \rightarrow[\mathrm{J}(\mathrm{s}) \rightarrow \mathrm{J}(\mathrm{M})]$ ', where ' $\mathrm{J}(x)$ ' stands for 'we are justified in believing $x$ true'. What we have to investigate is, then, whether the implication ' $\mathrm{C}(\mathrm{s}) \rightarrow \mathrm{C}(\mathrm{M})$ ' (which, for the sake of the argument, we take as a consequence of $[\mathrm{CH}]$ ) is either necessary or sufficient to motivate the S-M justificatory connection under indispensability, under the weak condition.

\subsubsection{Is confirmational holism necessary for premise (iii)?}

That confirmational holism might be unnecessary for IA has been already suggested, on different grounds, by several authors (e.g. Resnik [1995], Dieveney [2007], Azzouni 
[2009]), including Colyvan himself ${ }^{25}$. Taking much of this discussion for granted, what we are interested here is, as we have said, simply whether the implication ' $\mathrm{C}(\mathrm{s}) \rightarrow \mathrm{C}(\mathrm{M})$ ' needs to be assumed in order to defend our minimal (epistemic) versions of IA, especially whether it is required for upholding premise (iii) of [RE] and [PE]. In order for this to be the case, there must be no way of supporting the S-M justificatory connection without appealing to this implication. We shall argue that it is not so.

A first problem arises straightaway. Both our admissions that $[\mathrm{CH}]$ entails the implication ' $\mathrm{C}(\mathrm{s}) \rightarrow \mathrm{C}(\mathrm{M})$ ', and that one has no other ground than $[\mathrm{CH}]$ for arguing that $\mathrm{C}(\mathrm{s}) \rightarrow \mathrm{C}(\mathrm{M})$, have been conditioned by the weak condition. This last condition is, however, much weaker than that involved in the S-M justificatory connection under indispensability, namely that $\mathrm{M}$ is indispensable to $\mathrm{s}$. Hence, one could contend that, in the case where the latter condition obtains, i.e. when $\mathrm{M}$ is indispensable to $\mathrm{S}$, one should rely on grounds other than $[\mathrm{CH}]$ for arguing that $\mathrm{C}(\mathrm{s}) \rightarrow \mathrm{C}(\mathrm{M})$. Insofar as we are not at all willing to discard this possibility (that we rather consider favourably, as we shall see later), we suggest to firstly abstract from the supposition that $\mathrm{M}$ is indispensable to $\mathrm{s}$, by resting content with the weaker supposition that $\mathrm{S}$ and $\mathrm{M}$ are, respectively, a scientific and a mathematical theory and that the weak condition obtains. We want then, firstly, to argue against the view that, under this condition, endorsing the implication ' $\mathrm{C}(\mathrm{s}) \rightarrow \mathrm{C}(\mathrm{M})$ ' and then $[\mathrm{CH}]$ - is necessary for endorsing that justification to believe $\mathrm{M}$ is a necessary condition for having justification to believe that $\mathrm{S}$ is true. Let us call this last claim the ' $\mathrm{S}$ $\mathrm{M}$ justificatory connection', tout court. We can express it in symbols by: 'J(s) $\rightarrow \mathrm{J}(\mathrm{M})$ '. We shall come back later to the question whether, under the weak condition, the implication ' $\mathrm{C}(\mathrm{s}) \rightarrow \mathrm{C}(\mathrm{M})$ ' (taken as a consequence of $[\mathrm{CH}]$ ) is necessary to motivate the S-M justificatory connection under indispensability.

\footnotetext{
${ }^{25}$ Cf. Colyvan [2001], p. 37: “As a matter of fact, the argument can be made to stand without confirmational holism: it's just that it is more secure with holism. The problem is that naturalism is somewhat vague about ontological commitment to the entities of our best scientific theories. It quite clearly rules out entities not in our best scientific theories, but there seems room for dispute about commitment to some of the entities that are in these theories. Holism helps to block such a move since, according to holism, it is the whole theory that is granted empirical support". For discussion of this passage and other issues connected with holism in Colyvan's framework, cf. Peressini [2003, pp. 220-222].
} 
Our first point is as follows. Under some conceptions of science, like falsificationism, the link between the confirmation of a scientific theory and its justification is severed. In such conceptions, empirical confirmation of the (testable) hypotheses of a scientific theory s, whatever advantages may it deliver, and whatever it might be considered to consist in, will not essentially contribute to the justification of s. Still, even if one endorsed such views, one may of course still maintain, under the weak condition, the S-M justificatory connection, and, a fortiori, the S-M justificatory connection under indispensability. Even if it is conceded that confirmation is holistic, i.e. that $[\mathrm{CH}]$ is true, the fact that $\mathrm{C}(\mathrm{s}) \rightarrow \mathrm{C}(\mathrm{M})$ will simply play no role, in these views, to support the claim that $\mathrm{J}(\mathrm{S}) \rightarrow \mathrm{J}(\mathrm{M})$, under whatever supplementary condition.

Another way of showing that, endorsing the implication ' $\mathrm{C}(\mathrm{s}) \rightarrow \mathrm{C}(\mathrm{M})$ ' is unnecessary for endorsing that the S-M justificatory connection, under the weak condition, consists in noticing that this connection could be (vacuously) endorsed by anyone considered to have reasons for taking $\mathrm{M}$ to be justified independently of any consideration about its role in, or with respect to $\mathrm{S}$ (and, then, a fortiori, of M's being indispensable to $\mathrm{s}$ ). This would be the case, for example, for anyone that considered to have a priori reasons for believing in the necessary truth of $\mathrm{M}$ (and would then, at most, take its indispensability to s together with S's being justified as a welcome by-product): the S-M justificatory connection (and, $a$ fortiori, the S-M justificatory connection under indispensability) will be motivated without appealing to holism, nor to confirmation at all. This would make whatever empirical confirmation we can have for $\mathrm{s}$ (be its nature holistic or not) immaterial to the justification of M. Such an option will certainly not be welcomed by many supporters of IA. On the one hand, many of them also adopt a form of naturalism that ban a priori arguments. On the other hand, and most importantly, such an option seem to make IA pointless. Still nothing prevents one from accepting IA even under these circumstances ${ }^{26}$. In any case, what all this shows is that the S-M justificatory connection is, in general, conceptually independent of the notion of confirmation (and a fortiori of $[\mathrm{CH}]$ ), and is

\footnotetext{
${ }^{26}$ See Sereni [2013] for a way in which Frege may be taken to have reasons - based on considerations on applicability - for endorsing premise (iii), despite being alien to a holist conception of confirmation and to the idea that confirmation is relevant for the justification of mathematical theories.
} 
then so also under the weak condition. More generally, one of the basic idea underlying IA (cf. e.g. Putnam [1975], p. 74), that one cannot be a realist about science and at the same time an anti-realist about mathematics, needs not be supported by confirmational holism ${ }^{27}$.

Le us concede, now, both that (against the first point) empirical confirmation is an essential ingredient to the justification of a scientific theory (i.e. that $\mathrm{J}(\mathrm{s}) \rightarrow \mathrm{C}(\mathrm{s})$ ), and that (against the second point) we are after a defence of the S-M justificatory connection, under the weak condition, which is not based on having reasons independent of M's role in, or with respect to, s (possibly a priori ones) to believe in the necessary truth of $\mathrm{M}$. Since the S-M justificatory connection only consists in the implication ' $J(S) \rightarrow J(M)$ ', for the other implication ' $\mathrm{C}(\mathrm{S}) \rightarrow \mathrm{C}(\mathrm{M})$ ' to be necessary for this connection it must be the case that $(\mathrm{J}(\mathrm{s}) \rightarrow \mathrm{J}(\mathrm{M})) \rightarrow(\mathrm{C}(\mathrm{s}) \rightarrow \mathrm{C}(\mathrm{M}))$. But once one explores ways of defending this implication, it becomes apparent that it is unmotivated.

Insofar as we have conceded that confirmation of $\mathrm{s}$ is a necessary ingredient of its justification, what we have to consider is whether, under the weak condition, $[(\mathrm{J}(\mathrm{s}) \rightarrow \mathrm{C}(\mathrm{s})) \&(\mathrm{~J}(\mathrm{~s}) \rightarrow \mathrm{J}(\mathrm{M}))] \rightarrow(\mathrm{C}(\mathrm{s}) \rightarrow \mathrm{C}(\mathrm{M}))$. Suppose that $\mathrm{s}$ is justified. Then, for the premise of this implication, it follows that $\mathrm{S}$ is also confirmed and that also $\mathrm{M}$ is justified. If this were enough for concluding that $\mathrm{M}$ is confirmed, under the weak condition, our implication would be verified. But, why should be so? It would be so if, once $\mathrm{S}$ is justified, and then confirmed, the only way in which its justification could be transferred to $\mathrm{M}$, under the weak condition, were that s's confirmation transferred to $\mathrm{M}$, and that M's confirmation were sufficient for its justification. But this is clearly unmotivated. Why should the only way in which justification of $\mathrm{s}$ transfers to $\mathrm{M}$, under the weak condition, be through the transfer of s's confirmation to $\mathrm{M}$ ? We have assumed that confirmation of $\mathrm{s}$ is necessary for its justification, not that it is also sufficient; so it could well be the case that M's justification be due, under the weak condition, to ingredients of s's justification other than its confirmation. Moreover, why (both under the

\footnotetext{
${ }^{27}$ Putnam would clearly endorse premise (iii). But he has recently dispelled any doubt that his endorsing it hinges on holism: "I have never claimed that mathematics is 'confirmed' by its applications in physics" (cf. Putnam [2012, p. 188]).
} 
weak condition or not) should M's confirmation be sufficient for its justification? And why, anyway, should one be forced to admit that a mathematical theory is open to confirmation, in order to conclude that $\mathrm{M}$ is justified provided that $\mathrm{S}$ is so and the weak condition obtains?

The situation does not change essentially if the supposition that the confirmation of $\mathrm{S}$ is a necessary ingredient of its justification is replaced by the other supposition that the confirmation of $\mathrm{S}$ is sufficient of its justification. In this case, what we would have to consider is whether, under the weak condition, $[(\mathrm{C}(\mathrm{s}) \rightarrow \mathrm{J}(\mathrm{s})) \&(\mathrm{~J}(\mathrm{~s}) \rightarrow \mathrm{J}(\mathrm{M}))] \rightarrow(\mathrm{C}(\mathrm{s})$ $\rightarrow \mathrm{C}(\mathrm{M})$ ). Suppose that $\mathrm{S}$ is confirmed; then, for the premise of this implication, it follows that $\mathrm{M}$ is justified. Again, if this were enough for concluding that $\mathrm{M}$ is confirmed, under the weak condition, our implication would be verified. But, again, this is unjustified, as well as it is unjustified that, from these suppositions it follows that a mathematical theory is open to confirmation (both under the weak condition or not).

All in all, the only way of claiming that $[\mathrm{CH}]$ is necessary for the justification of the s$M$ justificatory connection under the weak condition is to assume that, under this condition, the confirmation of $\mathrm{S}$ and the justification of $\mathrm{M}$ are sufficient for the justification of $\mathrm{s}$ and for the confirmation of $\mathrm{M}$, that is, that $(\mathrm{C}(\mathrm{s}) \rightarrow \mathrm{J}(\mathrm{s})) \&(\mathrm{~J}(\mathrm{M}) \rightarrow$ $\mathrm{C}(\mathrm{M}))$, since it is easy to see that ${ }^{\mathrm{C}}[(\mathrm{C}(\mathrm{s}) \rightarrow \mathrm{J}(\mathrm{s})) \&(\mathrm{~J}(\mathrm{M}) \rightarrow \mathrm{C}(\mathrm{M})) \&(\mathrm{~J}(\mathrm{~s}) \rightarrow \mathrm{J}(\mathrm{M}))] \rightarrow$ $(\mathrm{C}(\mathrm{s}) \rightarrow \mathrm{C}(\mathrm{M}))^{\prime}$ ' is a tautology. Still, supposing that the confirmation of $\mathrm{s}$ is sufficient for its justification, is utterly implausible, since it results in disregarding the well-known issue that empirical confirmation will not distinguish between incompatible and still empirically equivalent theories, and that in most cases what bestows justification on a theory is, besides confirmation, a combination of many other virtues (some of which being even a priori), such as simplicity, unificatory power, explicatory power, ontological parsimony, fruitfulness. Moreover, supposing that the justification of $\mathrm{M}$ is sufficient for its confirmation requires admitting that a mathematical theory is open to confirmation, which is something that does seem to be required neither by the weak condition, nor by the S-M justificatory connection under this same condition. Of course, if this were admitted, and were also admitted that the justification of $\mathrm{M}$ is sufficient for its confirmation, one could add a supplementary conclusion to $[\mathrm{RE}]$ to the effect that the 
relevant mathematical theories are not merely justified, but also confirmed, but this is far from mandatory for [RE] to work.

Up to here, we have avoided considering $\mathrm{M}$ as indispensable to $\mathrm{s}$, by merely supposing that the weak condition obtains and investigating whether endorsing $[\mathrm{CH}]$ could be taken as necessary for endorsing the S-M justificatory connection under this condition. Let us now suppose that $\mathrm{M}$ is indispensable to $\mathrm{S}$, as any version of $\mathrm{AI}$ requires, and investigate whether endorsing $[\mathrm{CH}]$ could be taken as necessary for endorsing the s-M justificatory connection under indispensability, that is the premise (iii) of [RE] and [PE]. It seems to us that, in this case, even if one accepts that confirmation is relevant, necessary or even sufficient for the justification of $\mathrm{M}$, it become still more evident that $[\mathrm{CH}]$ is not required for the purpose. Indeed, if we take $\mathrm{M}$ as indispensable to $\mathrm{S}$, it is reasonable to expect that the grounds for arguing that $\mathrm{C}(\mathrm{s}) \rightarrow \mathrm{C}(\mathrm{M})$ should be sought in that very fact, i.e. in whatever intimate connection is established between $S$ and $M$ by the very fact that the latter is indispensable to the former. This is not to take for granted that the notion of indispensability, under whatever specification, together with the admission that $\mathrm{M}$ is indispensable to s (under the relevant specification), will be able by itself to deliver these grounds. As a matter of fact, arguing that it is so does should be one of the main tasks of a supporter of IA. The point is just that, once the indispensability of $\mathrm{M}$ to $\mathrm{S}$ is assumed, it is reasonable to expect that it, and it alone, would allow to claim that $\mathrm{C}(\mathrm{s}) \rightarrow \mathrm{C}(\mathrm{M})$, without requiring the help of $[\mathrm{CH}]$, which is, in fact, a much wider claim not constrained by an indispensability condition ${ }^{28}$.

The unpalatable consequences of the assumption of $[\mathrm{CH}]$ in IA when compared to actual mathematical practice-especially with the conscious use by scientists of false assumptions and idealizations - has been stressed by Maddy [1992] $]^{29}$. Apart from this, the

\footnotetext{
${ }^{28} \mathrm{Cf}$. the observation made at the very beginning of the present $\S 5.2$.

${ }^{29}$ Hellmann [1999] attempts at avoiding these and others unpalatable consequences by suggesting that even though confirmation is holistic and it is conceded that it is transferred from the testable hypotheses of a theory to its inner parts, it should not be taken to transfer equally, so that different parts of a theory, like those expressing idealized conditions, or mathematical hypotheses, could be taken to be confirmed to different degrees. Even if Hellman is right, his suggestion does not affect our present points concerning the non-necessity of confirmational holism for endorsing IA.
} 
main point, for us, is that $[\mathrm{CH}]$ is either irrelevant for AI (in the case in which no clear appropriate connection between justification and confirmation is admitted), or it is an overkilling (in the case in which this appropriate connection is admitted), since it delivers much more than it is actually required to defend IA, thus being an unnecessarily strong thesis $^{30}$.

Indeed, the mere fact that an appeal to indispensability is thought to be relevantwhich is already emphasised by the very expression 'indispensability argument' usually chosen to denote the argument under consideration-seems to be an indicator that such an argument essentially grounded on that notion, and not on the much wider one of confirmational holism.

True, holism is usually required to rule out the possibility that statements about theoretical or mathematical objects might be confirmation-resistant, as opposed to observational statements. However, if in [PE] one endorses, following Quine, a criterion for ontological commitment that is uniform across statements-i.e. based on the logical form of statements and content-neutral — one will have as a consequences that all entities whose existence is entailed by one's criterion will be said to exist, observational and theoretical alike. If one believes in the truth of premises $(i)-(i i i)$ of $[\mathrm{PE}]$, and has an uniform criterion of ontological commitment, confirmational holism, again, is not needed, for this purpose ${ }^{31}$.

${ }^{30}$ We shall come back in $\S 5.2 .2$ to the sufficiency of $[\mathrm{CH}]$ and the conditions it requires in terms of the connections between justification and confirmation.

31 One could claim, however, that some form of holism (presumably non-confirmational in nature) is somehow presupposed by any criterion of ontological commitment uniform across statements, namely in order to ensure that such a criterion uniformly applies both to scientific and to mathematical theories. Against this latter supposition, one could argue, for example, that the notion of aboutness employed in premise $(i v)$ cannot be given a content-neutral characterization, and does not apply to mathematical objects. A case in point is Azzouni's [1998, 2004] suggested alternative to [QC]. One could think, then, that an appropriate form of holism is required for rejecting this possibility. Notice, however, that this is far from necessary: even if some understanding of [QC] or, better, some specification of the schematic notion of aboutness employed in premise (iv) of [PE] and [PnE] (or of other schematic notions employed in some of our versions of IA), turned out somehow to presuppose some form of holism, this would leave untouched that an epistemic version of IA, and, then, a fortiori, IA as such, do not necessarily require any appeal to it; 


\subsubsection{Is confirmational holism sufficient for premise (iii)?}

As regards the sufficiency of endorsing $[\mathrm{CH}]$ for endorsing premise (iii) of $[\mathrm{RE}]$ and $[\mathrm{PE}]$, things are by far simpler. Since, both supposing that $\mathrm{M}$ is indispensable to $\mathrm{s}$, or, merely, that the weak condition obtains, in order to draw the implication ' $\mathrm{J}(\mathrm{s}) \rightarrow \mathrm{J}(\mathrm{M})$ ' from the other implication ' $\mathrm{C}(\mathrm{s}) \rightarrow \mathrm{C}(\mathrm{M})$ ', it is necessary and sufficient to admit that $\mathrm{J}(\mathrm{s})$ $\rightarrow \mathrm{C}(\mathrm{s})$ and $\mathrm{C}(\mathrm{M}) \rightarrow \mathrm{J}(\mathrm{M})$. Hence, for premise (iii) of $[\mathrm{RE}]$ and $[\mathrm{PE}]$ to follow from $[\mathrm{CH}]$ it is sufficient that confirmation for the relevant scientific theories is taken to be necessary for their justification, and confirmation for the relevant mathematical theories is taken to be sufficient for their justification. Moreover, if we suppose that, when confronted with the relevant theories $\mathrm{S}$ and $\mathrm{M}$, one has no other ground than $[\mathrm{CH}]$ for arguing that $\mathrm{C}(\mathrm{s}) \rightarrow \mathrm{C}(\mathrm{M})$, these two conditions (taken together) are also necessary. Under this supposition, wondering whether endorsing $[\mathrm{CH}]$ is sufficient for endorsing premise (iii) of $[\mathrm{RE}]$ and $[\mathrm{PE}]$ reduces to wondering whether confirmation for the relevant scientific theories is necessary for their justification, and confirmation for the relevant mathematical theories is sufficient for their justification.

The former of these conditions could be questioned, but it seems to us to be safely admissible, in general, that is, for most of our scientific theories ${ }^{32}$. For it is plausible to grant that, in general, any virtue a scientific theory may have will not confer justification to it in absence of confirmation.

The latter condition is more questionable, instead. One reason of this has already been at most this thesis would be involved in some particular instances of such an argument (just as it happens for IBE: cf. footnote 35 below).

${ }^{32}$ One could, however, question this condition in some quite particular cases, as those involving highly theoretical physical theories, for example string theory. One could indeed maintain that in cases like these, the relevant scientific theories can be justified, and are actually considered to be so, independently of any empirical confirmation they may receive or have received. It is more likely, however, that in the complete absence of empirical confirmation we would not take ourselves to be justified, however weakly, in taking a scientific theory to be true; rather, such scientific theory will be said to enjoy a number of virtues that will merely make it acceptable in the scientific community for many practical and theoretical purposes. Nonetheless, this form of acceptance, it goes without saying, will not be strong enough to support the conclusion(s) of IA, in any of the versions we have discussed here. 
mentioned: consenting to it requires admitting that mathematical theories are open to confirmation, which could be plausibly questioned (and is, in any case, nor required for endorsing IA). Another reason is that contending that confirmation of a mathematical theory, whatever it might be taken to be, is sufficient for its justification results in disregarding any a priori virtue that such a theory could have as a necessary ingredient of its justification. Finally, even someone, presumably endorsing a proto-empiricist view on mathematics, who is ready to admit that mathematical theories are open to confirmation, and that no a priori virtue of a mathematical theory is required for it to be justified (when it is well supported by a posteriori or empirical evidences) could face that the same difficulty raised above $(\S 5.2 .1)$ for the thesis that confirmation of a scientific theory is sufficient for its justification also applies, mutatis mutandis, in the case of mathematical theories.

\subsection{Can we dispense with naturalism?}

What about now premise $(i)$ of $[\mathrm{RE}]$ and [PE]? Do we need to assume naturalism, in any form, in order to claim that we are justified in believing some scientific theory to be true? What seems clear is that some form of scientific realism will have to be assumed. For a fairly standard characterization, we can describe scientific realism as the thesis that our mature scientific theories are true, or, at least, approximately true descriptions of an external, mind-independent reality, that their statements should be interpreted at face value (both when they speak of observable entities and when they speak of theoretical ones), and that the objects of which they speak do inhabit the world (cf. Psillos [1999, p. xix] for a more extended definition on these lines). In order to defend premise $(i)$ in $[\mathrm{RnE}]$ and $[\mathrm{PnE}]$, we need to maintain that there are true scientific theories, and this implies a form of scientific realism. Moreover, some arguably milder form of scientific realism will be needed also for defending premise $(i)$ in $[\mathrm{RE}]$ and $[\mathrm{PE}]$. This milder form of realism should at least accept that we are justified in believing that there are true scientific theories (without necessarily taking the further step of claiming that there are, or were, or will be some such) ${ }^{33}$.

\footnotetext{
${ }^{33}$ Notice that scientific realism, as formulated here, entails that (we are justified to believe that) the
} 
Now, scientific realism, in one form or other, is likely to be a basic assumption underlying naturalism. Quine himself listed "unregenerate realism" among the sources of naturalism (Quine [1975], p. 72). But in order to justify premise (i) of [RE] and [PE] only some form of scientific realism is needed, and whereas naturalism implies (or might imply, depending on the chosen formulation) scientific realism, the latter does not imply the former. Where naturalism hinges on endorsing that scientific theories are the only source of genuine knowledge, with the result that we are justified in believing to be true only these theories or those whose truth follows from the latter's truth, scientific realism only implies that scientific theories are a kind of theories in whose truth we are allowed to be justified. This is not to deny that realism can be fruitfully combined with a naturalist position. It can even be maintained that the adoption of naturalism facilitates - since it implies it - the adoption of scientific realism. However, nothing prevents someone who believes, for example, that genuinely philosophical a priori arguments are a reliable source of knowledge, from believing, provided that conflicting results are avoided, that (mature, predictively successful, well-confirmed, etc.) scientific theories are sufficiently reliable sources too. It is not difficult to think of scientific realists that are not naturalists. For an illustrious case, consider Frege, who had realistic views about scientific inquiry but surely was not a naturalist, as his views on mathematics show.

It then seems that insofar as endorsing [NAT] requires (entails) endorsing scientific realism, the former could thus well be a sufficient for endorsing premise $(i)$ of $[\mathrm{RE}]$ and $[\mathrm{PE}]$, but clearly it is not necessary ${ }^{34}$.

entities (both observable and theoretical) which are spoken of in mature scientific theories exist (at least, if we admit that a statement of a scientific theory cannot be true if these entities does not exist). Some remarks are in order. First, one may adopt forms of realism-e.g. structural realism - where the existence of these individual entities is not entailed; this version of realism would still be adequate to motivate premise $(i)$ in all minimal arguments. Second, it would be odd to assume that scientific realism entails either the existence of the mathematical entities mentioned in mathematical statements, or that the mathematics used in science is true; assuming scientific realism does not beg the question with regards to the conclusion of neither platonist or realist versions of IA, and can be safely assumed in both.

${ }^{34}$ To our knowledge, the only other version of IA which is explicitly claimed by its proponent to dispense with naturalism is the one offered by Azzouni [2009]. We'll discuss this below. 
This being established, one could still wonder whether endorsing [NAT] is either necessary of sufficient for endorsing another premise of $[\mathrm{RE}]$ and $[\mathrm{PE}]$. The only plausible candidate for this is premise (iii), which plays in these arguments the role that premise ( $i$ ) of Colyvan's argument plays in this latter argument. As we have mentioned in $\S 2$, Colyvan indeed argues that naturalism is required in order to justify the onlydirection of this latter premise. Still, we have also already observed that this direction is, in fact, useless for drawing the argument's conclusion, and has, accordingly, no correlate in premise (iii) of [RE] and [PE].

At most, then, one can argue that the endorsement of [NAT] is necessary for endorsing a strengthened variant of this premise, that would state that we are justified in believing true all and only the mathematical theories that are indispensable to scientific theories that we are justified in believing to be true. This variant would still be involved only in variants of $[\mathrm{RE}]$ and $[\mathrm{PE}]$ whose conclusions are, in turn, strengthened variants of the conclusions of these arguments, stating not only sufficient conditions for our being justified, respectively, in believing true the relevant mathematical theories, and in believing the objects which these are about to exist.

\section{Retrieving common arguments from the minimal arguments}

It is easy to see how the suggested minimal versions of IA could serve as a basis for the stances on IA represented by Putnam's, Colyvan's and Baker's arguments, respectively (cf. § 2). Putnam's argument is nothing but a variant of [PnE] (or, depending on the reading of Putnam's text, [PE]). Colyvan's argument is a variant of the epistemic version of IA that results from adding to premise (iii) of [PE] the redundant assumption that we are justified in believing true only the mathematical theories that are indispensable to scientific theories that we are justified in believing to be true ${ }^{35}$. Finally, as anticipated at the end of $\S 4$, Baker's Enhanced Indispensability Argument, can be retrieved from $[\mathrm{PE}]$ once an appropriate equivalence relation $\varepsilon$ is selected in the

35 Together with what we have said in $\S 5.2 .1$, this entails that Colyvan's argument is, in fact, independent of confirmational holism, despite his own initial claim in Colyvan [2001, p. 12] (cf. the quote relative to footnote 5 ; but cf. also footnote 24$)$. 
specification of the notion of (in)dispensability, e.g. the relation of having the same explanatory power ${ }^{36}$.

Things are more complex with arguments in the pragmatic stance.

Let us begin with Resnik's. This is very different in form from all other representative versions of IA that we have reviewed. It seems clear that it dispenses with confirmational holism $^{37}$. It is instead not clear whether it also dispenses from naturalism. According to Resnik himself the passage from its premise (vi) to (vii) is justified, by naturalism, which he briefly defines as the thesis that "natural science is our ultimate arbiter of truth and existence" ${ }^{38}$, and considers as suitable for ruling out scepticism about the justification and truth of our scientific theories. Still, it is not clear how naturalism can warrant the passage from the justification of some theories, and particularly of mathematical ones, to their truth, a passage which is surely hard to secure. More generally, it is far from clear that Resnik argument be valid (or admit, at least, a valid rephrasing). It is thus not surprising that it is hard to retrieve it from our minimal versions, which are clearly valid. This remains, however, an unicum with respect to the ongoing debate.

Notice, on the other hand, that it is not clear whether the role played by the notion of justification in Resnik's argument is in any sense cognate to that played by it in our minimal arguments. We take justification as applying to statements or bodies of statements, and as being justification for their truth, and not just for their adoption for whatever practical reasons. Resnik does firstly conceives justification as applying (if not uniquely, also) to acts, rather than bodies of statements; and secondly he bases our

\footnotetext{
${ }^{36}$ Discussion of the Enhanced Indispensability Argument often pertains to the alleged role that inference to the best explanation (IBE) may have in IA. Still, insofar as the minimal version of this argument, provided by [PE] under the mentioned specifications, is concerned, no appeal to IBE is required, and its validity need then not be presupposed. This does not mean that IBE cannot be involved in any specification of the minimal versions of IA. Indeed, it could be involved in some such specifications in two ways: the equivalence relation $\varepsilon$ in the schematic definition of the notion of (in)dispensability could be specified through the notion of explanation in a way that presupposes the validity of IBE; or the criterion of virtuosity $\alpha$ in that same definition could itself presuppose the validity of IBE.

${ }^{37}$ This is what Resnik himself seems to imply in the quote relative to footnote 10.

${ }^{38}$ Resnik [1995, p. 166; 1997, p. 45].
} 
"accepting as true such mathematics as science uses" on the pragmatic reason that "we are justified in doing science" and that science, when considered in its practice, proceeds through various mathematical assumptions - and not rather on the fact that any scientific theory is even approximately true. If Resnik's argument were (valid and) sound, this could be see as an advantage, since it would make the argument independent of the supposition that some scientific theories are true. If (valid and) sound, this argument would thus dispense with scientific realism, as Resnik [1997, pp.46-47] suggests (and this should be so despite Resnik's quite doubtful claim that the passage from conclusion (vi) to conclusion (vii) depends on naturalism, understood as the thesis that "natural science is our ultimate arbiter of truth and existence", a thesis which could hardly be taken as independent from a form of scientific realism).

Let us consider now Azzouni's argument, namely his Assertoric-use QP ${ }^{39}$. It deserves more careful consideration, since it is the one that comes closest to resembling, at least in spirit, some of our suggested minimal version, as least insofar as it is, and, as we said in $\S$ 2 , explicitly meant to avoid presupposition of either holism or naturalism ${ }^{40}$. Also the distinction between arguments for mathematical realism and for platonism is suggested by Azzouni [2004], who questions [QC] and argues at length that IA can at most be an argument for the truth of mathematical theories, but that it falls short of supporting platonism $^{41}$.

The first thing to be noticed is that Azzouni's Assertoric-use QP stems from an interpretation of the "enthymematic blueprint" quoted above in $\S 2$, but is not regimented in the form of a codified non-enthymematic (valid) argument with enumerated and explicitly stated premises and conclusion(s). Enquiring whether it can be retrieved from one of our minimal versions of IA requires, then, a reinterpretation of Azzouni's proposals.

Prima facie, given that there is no mention of epistemic notions like justification in Azzouni's blueprint, the relevant minimal version of IA with which his argument should

\footnotetext{
${ }^{39}$ Cf. $\S 2$, above.

${ }^{40}$ Azzouni [2009], especially p. 147, fn. 11.

${ }^{41}$ Cf also Azzouni [2009], p. 140, note 2; p. 147, note 11.
} 
be compared seems to be $[\mathrm{RnE}]$. However, the way in which Azzouni motivates the passage from the blueprint to the Assertoric-use QP suggests another option.

Azzouni's strategy for obtaining the Assertoric-use QP depends, firstly, on the specification of the single premise of the former, i.e. 'certain statements that quantify over mathematical entities are indispensable to science', as the claim that the "assertoric use" of the relevant statements, which quantify over mathematical entities, is indispensable to science. According to Azzouni ${ }^{42}$, it is an empirical fact that people use certain statements assertorically while doing science, for the two aims of presenting statements as following from other statements previously made ("deductive use") and of describing state of affairs ("representational use"). A second empirical fact is said to be e $^{43}$ that given our ordinary understanding of the word 'true', the assertoric use of a statement $p$ entails, via Tarksi's biconditionals, the commitment of those who assertorically use $p$ to the truth of $p$. From this second empirical fact, it follows that the conclusion of the blueprint should be intended as the claim that we are committed to the truth of those statements whose assertoric use is indispensable to science. Although different readings can be given to the expression 'we are committed to the truth of $p$ ', we take it that the more plausible one, consistent with Azzouni's discussion, is as 'we are justified in believing $p$ true ${ }^{44}$. Assuming that this is so, it follows that the most appropriate among our minimal versions of IA to be compared with Azzouni's Assertoric-use QP is [RE].

Two questions arise here: whether Azzouni's version of IA is eventually to be

${ }^{42}$ Cf. Azzouni [2009, p. 140-141].

${ }^{43}$ Ibidem, p. 141.

${ }^{44}$ The sense in which we are justified in believing a mathematical statement true is meant, however, to be in some sense "stronger" [cf. Azzouni 2009, p. 147] than that licensed by Resnik's argument on pragmatic grounds: as Azzouni claims, "it isn't that we're 'justified' in describing an assertorically-used sentence as true; Tarski biconditionals make the use of the truth predicate nonnegotiable". Whatever this distinction comes to in details, it does not seem that from the assertoric use of a statement $p$ the truth itself of $p$ can follow, over and beyond our commitment to take $p$ as true. Even if this entails that the conclusion of the Assertoric-use QP will be, as a matter of fact, a different, epistemic, version of the conclusion of Azzouni's proposed blueprint (i.e. 'Those statements are true'), we still see this as the most reasonable outcome of Azzouni's discussion; we acknowledge, however, that this reading can be subject to controversy depending on how our "commitment" to the truth of a statement is understood. 
considered more minimal than $[\mathrm{RE}]$; and whether his version can indeed be retrieved from $[\mathrm{RE}]$.

As to the first question, a clue for a positive answer could come from the fact that [RE] appeals to the notion of truth (thought of as a schematic notion, variously specifiable), whereas Azzouni's argument doesn't explicitly appear to do so. Still, the latter relies on the fact that assertoric use of mathematical statements is indispensable to scientific practice, and this is taken to entail commitment to the truth of these statements just in virtue of the Tarskian biconditionals which "transform assertoric uses into truth-commitments" ${ }^{\prime 4}$. Moreover, Azzouni argues ${ }^{46}$, that "if I assertorically use a sentence ${ }^{47}$, I recognize myself as bound by implication to the original sentence prefixed by 'It's true that ... ,", which results in maintaining that there is a rather intimate connection between assertion and truth. But if this is so, then truth, if not explicitly used in the premises of the argument, is presupposed by the very notions of assertion and assertoric use by means of which the argument is built. It may even well be explicitly mentioned in a premise of the argument once all its underlying assumptions are brought to the fore ${ }^{48}$. Hence, if the issue is the appeal to some notion of truth, then, it is far from clear that Azzouni's argument is in any sense more minimal than [RE].

A second related clue for a positive answer to the first question is that the conclusion of Azzouni's Assertoric-use QP appears to be derived without explicitly assuming that we are justified in believing some scientific theories to be true. However, as Azzouni himself acknowledges ${ }^{49}$, his argument has as accompanying premise "the $a u$-indispensability of

${ }^{45}$ Azzouni [2009], p. 142.

${ }^{46}$ Azzouni [2009], p. 141.

${ }^{47}$ Azzouni seems to indifferently use in his paper the terms 'sentence' and 'statement'. While maintaining the term 'sentence' in all our quotations from Azzouni's paper where it occurs, we shall, instead, invariably use the terms 'statement', as we do throughout our paper.

${ }^{48}$ Notice that no particular conception of truth is presupposed in our minimal versions, so that one is at liberty to use whatever notion one prefers in the specification of the schematic arguments (included a disquotational one). Hence, the question here is not whether we, as opposed to Azzouni, make use of some particular conception of truth, but whether any notion of truth is involved at all in the relevant versions of IA.

\footnotetext{
${ }^{49}$ Azzouni [2009], p. 144.
} 
the scientific sentences themselves (given a commitment to the scientific project)", where the term 'au-indispensability' is a shortened form of 'indispensability of the assertoric use'. It seems, moreover, plausible, in the light of our previous discussion, to understand the commitment to the scientific project as a justification in the truth of these scientific statements, and then, presumably, in some scientific theories.

Be that as it may, these considerations suggest that Azzouni's argument is possibly not to be considered more minimal than [RE], but rather very close to it, at least in spirit. We should then move to our second question.

What we have said so far suggests to specify both the single premise and the conclusion of Azzouni's blueprint by making explicit the assumption of our commitment to the scientific project intended as a commitment to (the truth) of those statements whose assortoric use is indispensable to this project, and to state the conclusion in an epistemic form. The ensuing formulation will thus be this:

\section{Assertoric-use QP (I)}

i) We are committed to (the truth of) those statements that are $a u$-indispensable to the scientific project;

ii) Some statements that quantify over mathematical entities are au-indispensable to the scientific project;

iii) We are committed to (the truth of) these statements.

Above we have mentioned the accompanying premise of Azzouni's argument concerning the "au-indispensability of the scientific sentences themselves". The whole passage where this premises is put forward seems to suggest that the indispensability of the assertoric use of the relevant statements that quantify over mathematical entities is to be, as it were, split into the $a u$-indispensability of both some scientific and some mathematical statements. It goes as follows ${ }^{50}$ : "I [...] read the premise of the ethymemic blueprint of the QP as stating that many sentences of mathematics are $a u$-indispensable to science. Accompanying this premise is the assumption of the $a u$-indispensability of the scientific

\footnotetext{
${ }^{50}$ The reference is, of course, the same as in footnote (48).
} 
sentences themselves (given a commitment to the scientific project)". The statements that quantify over mathematical entities and are $a u$-indispensable to the scientific project mentioned in Asseroric-use QP (I) seem here to be those that in this passage are referred to as 'sentences of mathematics [that] are $a u$-indispensable to science" ${ }^{\prime 1}$. This suggests that the statements here referred to as 'the scientific sentences themselves' do not quantify over mathematical entities, but are such that they can be assertorically used only if some mathematical statements (which rather do) are so used (for example insofar as the former involve individual or predicate constants defined though the latter). It would follow that the $a u$-indispensability to the scientific project of the mathematical statements mentioned in Asseroric-use QP (I) just depends on this, namely on their being such that those scientific statements whose assertoric use is indispensable to the scientific project are such that they can be assertorically used only if these mathematical statements are so used. If we express this condition by saying that the latter statements are $a u$-indispensable to the former, Assertoric-use QP (I) can then be restated and further expanded as follows:

\section{Assertoric-use QP (II)}

i) We are committed to (the truth of) those statements that are $a u$-indispensable to the scientific project;

ii) Some mathematical statements are $a u$-indispensable to some statements that are $a u$-indispensable to the scientific project;

iii) We are committed to the truth of those statements that are $a u$-indispensable to the scientific project only if we are committed to the truth of those mathematical statements that are $a u$-indispensable to them;

iv) We are committed to (the truth of) these mathematical statements.

This latter version of IA is clearly similar, in structure and content, to [RE]. Once it is conceded that 'being commitment to the scientific project' can be interpreted as 'being justified in believing some scientific theories to be true', premise (i) of Assertoric-use QP

\footnotetext{
${ }^{51}$ Cf. footnote (46) above.
} 
(II) can, indeed, be conceived as a specification of premise ( $i)$ of [RE]. Following Azzouni, one may say that the former is justified by the empirical fact that when we assertorically use a statement $p$, we are committed (via Tarski biconditionals) to the truth of. If premise (ii) of [RE] is then specified by employing the notion of assertoric use in the specification of the $\varepsilon$ equivalence relation involved in the schematic notion of indispensability - so that the assertoric use of certain mathematical statements turns out to be indispensable to the assertoric use of those scientific statements that we must assertorically use if we are committed to the scientific project - what one gets is just premise (ii) of Assertoric-use QP (II). As regards premise (iii), it is easy to see that the s-M justificatory connection can be specified by considering that the commitment to the truth of the statements of s, following via Tarski biconditionals from their assertoric use, can be granted only in presence of a similar commitment, via the same route, for the mathematical statements of $\mathrm{M}$ that are $a u$-indispensable to $\mathrm{s}$ : this is does not seem to add nothing that Azzouni would not consider as implicit in his own argument ${ }^{52}$. Premise (iii) of Assertoricuse QP (II) just results from this specification of premise (iii) of [RE], with the implicit assumption that assertoric use of $p$ entails commitment to the truth of $p$. Once [RE] is appropriately specified, then, the conclusion of Assertoric-use QP (II) is nothing by an alternative though equivalent formulation of the conclusion of [RE], as one may expect by alternative versions of an argument that are meant to support a common conclusion.

If we are correct, and Assertoric-use QP (II) is a plausible reconstruction, in explicit

${ }^{52}$ Notice also that Azzouni explicitly objects to forms of fictionalism that constitute the most obvious strategies for rejecting premise (iii). In the following passage (Azzouni [2009], p. 143), it is easy so read something very close to the suggested specification of premise (iii) of [RE]:

One issue to be explored in this paper is whether the assertoric use of many statements of ordinary science is compatible with one or another construal of the mathematical statements utilized in science as not assertorically used (and therefore, as either not true-apt or as false). I'll show that a position that takes us as truthcommitted to statements in any area where mathematics is applied, while assuming that we aren't simultaneously truth-committed to that mathematics, is unstable.

This, if needed, seems to be another piece of evidence that premise (iii) can be upheld without appealing to confirmational holism. 
non-enthymematic form, of the version of IA that Azzouni has in mind, then it seems susceptible of being retrieved from [RE] through appropriate specifications of the notions involved $^{53}$.

\section{The philosophical significance of the indispensability argument}

Much of the recent discussion on IA has focused on holism and naturalism. Many authors have either criticized IA, taking Colyvan's as the most relevant formulation, or offered alternative versions of it. Both supporters and critics, with few exceptions we have mentioned above, take naturalism and holism to be essential to this argument, or, more generally, to what is usually referred to as 'the Quine-Putnam Indispensability Argument', and discuss the alleged dependence of the argument on these doctrines. For example, Maddy [1992, 2007] claims that IA fails because of inescapable clashes between the notions of holism and naturalism (as Quine conceived of it) and essential features of mathematical and scientific practice and methodology; relying on a nonholistic notion of confirmation, Sober [1993] argues that empirical evidence cannot even indirectly justify mathematical theories.

As it turns out, minimal versions of IA can be devised that are far less demanding than the so-called Quine-Putnam Indispensability Argument. Only scientific realism (beyond, obviously, a proper characterization of (in)dispensability) will be an essential ingredient in justifying premise $(i)$ in [RE] and [RnE]. In order to obtain a platonist conclusion, thus to support $[\mathrm{PE}]$ and $[\mathrm{PnE}]$, only an appropriate criterion for ontological commitmentarguably, Quine's ${ }^{54}$ — needs to be further assumed (together with what is needed to justify

\footnotetext{
${ }^{53}$ This is, of course, not intended to suggest that Azzouni's Assertoric-use QP is already included, in nuce, in $[\mathrm{RE}]$. What we argue is rather that $[\mathrm{RE}]$ is schematically general enough in order to provide an argument form that Azzouni's Assertoric-use QP (which, as a matter of fact, has been offered beforehand and independently of $[\mathrm{RE}])$ can be taken to instantiate via appropriate specifications.

${ }^{54}[\mathrm{PE}]$ or $[\mathrm{PnE}]$ can be seen as instances of a general way in which Quine would draw ontological conclusions. One might object that the minimal formulation would make nothing of the special subject matter of mathematics (thanks to Matti Eklund for raising this). However, we don't find anything, in
} 
the remaining premises).

It is often thought that IA is especially suited for those mathematical (semantical or ontological) realists working in a broadly empiricist framework. As Shapiro claims,

indispensability arguments are anathema to those, like the logicists, logical positivists, and neologicists, who maintain the traditional views that mathematics is absolutely necessary and/or analytic and/or knowable a priori ${ }^{55}$.

This is an obvious philosophical outcome for versions of IA that proceed under the assumption of naturalism and deliver necessary conditions for their conclusions (cf. the end of $\S 5.3$ ). But this need not be so: when naturalism is left out of the picture, the argument only gives sufficient conditions for either semantic realism or platonism.

Clearly, if we espouse a naturalist ideology, we will better make our argument for mathematical (semantic or ontological) realism rely, more or less explicitly, on naturalism, and thus secure (semantic or ontological) realism in a way that is consistent with our naturalist viewpoint. But it is not, as it were, in the very nature of IA to give sufficient and necessary conditions for its conclusions. It might just be our particular interest to have a version of it giving both.

IA is not a naturalist argument per se. We see no ban in principle, for those who believe in the a priori character of mathematical truths, against the acceptance of

Quine's reluctant acceptance of platonism, like assuming something special about mathematics and building a form of IA on this (contrary to what is suggested by Steiner's [1978, pp. 19-20] "transcendental" interpretation of IA). The special character of mathematics seems rather to be proved by the very fact that we cannot dispense with it in science. All posits are ontologically on a par until we are faced, as Quine would call it, with an unabridged language of science. Not all posits will come out indispensable. Propositions and meanings don't. Mathematics does.

${ }^{55}$ Shapiro [2005], pp. 13-14. Shapiro remarks is only cursorily made, and nothing special hinges on it in his discussion; we just take it as an indication of a widespread feeling. 
indispensability arguments ${ }^{56}$. Modest anti-naturalists of this $\operatorname{sort}^{57}$ will claim at most that IA is superfluous, or ancillary, since they can offer reasons for the same conclusion(s) that are by far more certain than the contingent grounds on which IA hinges. But this is definitely different from rejecting the argument.

The point is that the real anathema for all those philosophers listed by Shapiro in his quotation is not IA itself: it is naturalism. Any argument relying on naturalism will be anathema for them: IA can, but need not, be a good candidate.

On this respect, it is remarkable that, after long time, Putnam himself recently felt the need of making his voice heard again in this debate. Commenting on Colyvan's argument, Putnam clearly remarks that the 'only' direction of premise $(i)$ of this argument - the one committing a supporter of the argument to naturalism-expresses a thesis he "never subscribed to in [his] life" 58 . He stresses that his adoption of IA was meant to show — as already suggested in Putnam [1971] and [1975b] — that it is incoherent to adopt scientific realism and at the same time reject (semantic) realism about mathematics. Moreover, he was explicit in claiming that

nevertheless, there was a common premise in my argument and Quine's [...] That premise was "scientific realism", by which I meant the rejection of operationalism and kindred forms of "instrumentalism". I believed (and in a sense Quine also believed) that fundamental physical theories are intended to tell the truth about physical reality, and not merely to imply true observation sentences ${ }^{59}$.

At the very least, our conclusions can be seen as a way of setting the debate straight to its origin, and showing that the minimal versions of IA are more closely related than others to Putnam's argument.

${ }^{56}$ Some of Frege's remarks [1893-1903, §91] have sometimes be taken as a statement of a form of IA in nuce (but see Garavaso [2005] and Sereni [2013]). But it would be utterly implausible to claim that anything like IA was Frege's main argument for believing in the existence of mathematical objects.

${ }^{57}$ Radical anti-naturalists, like sceptics, would deny that science is any source of knowledge at all.

${ }^{58}$ Cf. Putnam [2012, p. 183].

59 Ibid. The 'in a sense' qualification concerns Quinean themes (indeterminacy of translation, differences with a standard realist view of language) discussed in Putnam [1988]. They do not affect our present point. 
If IA is meant as delivering only sufficient conditions for its conclusions, there is a clear sense in which it is being revisionary with respect to Quine's original views. In a number of different passages Quine makes controversial claims about parts of mathematics (higher set-theory, for example) that have no applications in empirical sciences, and are a fortiori not indispensable to scientific theories. Quine denies that the mathematical objects to which those parts of mathematics are committed to deserve any ontological rights (he famously spoke of "mathematical recreation" ${ }^{60}$ ). This attitude has engendered quite a wide debate ${ }^{61}$. If indispensability (in versions of IA for platonism) is, as it were, the mark of existence for mathematical objects, then the objects of unapplied mathematics are banned from our ontology.

It is indeed possible to maintain a version of IA for which naturalism is necessary. This argument delivers the sort of platonism that Quine endorsed. But this argument is in tension with many forms of platonism, which would not distinguish among the ontological rights of different parts of mathematics, not at least on grounds of applicability and indispensability (Maddy has long insisted on this; see e.g. Maddy [2005]). It could even be argued that such an argument is not an argument for platonism (as standardly conceived), but rather for the proto-empirical (or "quasi-empirical", to borrow from Putnam [1975b, p. 62 $]^{62}$ ) character of mathematics.

Versions of IA giving only sufficient conditions leave open the possibility that we are justified in believing that unapplied mathematical theories are true, or that the objects they are about exist, wholly independently of IA: IA is understood as an argument for

${ }^{60}$ Quine [1986, p. 400]. In later writings, Quine admitted that this would create an unjustifiable asymmetry between different parts of mathematics, hence he resorted to the idea that we cannot completely deny meaningfulness to unapplied parts of mathematics, but that we can arbitrarily decide whether to call those parts true or false (cf. Quine [1995, p. 56-57]).

${ }^{61}$ Cf. Parsons [1983], Maddy [1992], Leng [2002; 2010], Colyvan [2007]. Putnam [1971], p. 346-7, suggests a view similar to Quine's on unapplied mathematics. His is however a milder position (unapplied mathematics "should today be investigated in an 'if-then' spirit"), and he is wary of restricting his claims to "the case for 'realism' developed in the present section".

62 According to Putnam [1975b], mathematics could count as quasi-empirical in that we can account for it in terms of quasi-empirical methods of inquiries (other than deductive proof from axioms) based on successful applications. This is for Putnam consistent with a non-platonist interpretation of mathematics. 
mathematical (semantic or ontological) realism among others, not as the only argument.

If Quine suggests that a proper indispensability argument hinges on naturalism, then, it is only because he was a naturalist on independent grounds in the first place. Nothing in the argument mandates that this is so. That is just an example of the philosophical use of the argument (in a non-minimal version) that can be made in an empiricist framework. It is not a philosophical outcome that the argument can secure by itself. 


\section{Acknowledgements}

Earlier versions of this paper have been presented on several occasions in seminars and conferences. The authors wish to thank all the audiences for their helpful comments. Special thanks go to: Andrea Bianchi, Francesca Boccuni, Jacob Busch, Annalisa Coliva, Matti Eklund, Mario De Caro, Jan Lacki, David Liggins, Paolo Mancosu, Sebastiano Moruzzi and Eva Picardi. Many thanks also to two anonymous referees for this volume, who provided precious suggestions.

\section{References}

Armstrong, D. [1997], A World of States of Affairs, Cambridge University Press, Cambridge.

Azzouni, J., [1998], “On 'On What There Is"”, Pacific Philosophical Quarterly, 79, 1998, pp. 1-18.

- [2004], Deflating Existential Consequence. A Case for Nominalism, Oxford University Press, Oxford-New York.

- [2009], "Evading Truth Commitments: the Problem Reanalyzed", Logique \& Analyse, 206, pp. 139-176

Baker, A., [2005], “Are there Genuine Mathematical Explanations of Physical Phenomena?", Mind, 114, 2005, pp. 223-238.

- [2009], "Mathematical Explanation in Science", British Journal for the Philosophy of Science, 60, 2009, pp. 611-633.

Colyvan, M., [2001], The Indispensability of Mathematics, Oxford University Press, Oxford-New York.

- [2007], "Mathematical Recreation Versus Mathematical Knowledge”, in M. Leng, A. Paseau, M. Potter (eds.), Mathematical Knowledge, Oxford University Press, Oxford-New York, 2007, pp. 109-22.

Craig, W., [1956] “Replacement of Auxiliary Expressions”, Philosophical Review, 65, 1956, pp. 38-55.

Dieveney, P. S., [2007], "Dispensability in the indispensability argument", Synthese, 157, 2007, pp. 105-128. 
Dummett, M., [1978], "Realism", in Dummett, M., Truth and Other Enigmas, Duckworth, London, 1978.

Field, H., [1980], Science Without Numbers, Blackwell, Oxford.

— [1989], Realism, Mathematics and Modality, Blackwell, Oxford.

Frege, G., [1893-1903], Grundgesetze der Arithmetik, H. Pohle, Jena, 1893-1903 (2 Voll.)

Garavaso, P., [2005], “On Frege’s Alleged Indispensability Argument”, Philosophia Mathematica (III), 13, 2005, pp. 160-173.

Hafner, J., Mancosu, P., [2005], “The varieties of mathematical explanation”, in P. Mancosu et al. (eds.), Visualization, Explanation and Reasoning Styles in Mathematics, Springer, 2005, pp. 215-250.

Hellman, G., [1989], Mathematics without numbers, Oxford University Press, OxfordNew York.

Hellman, G, [1999], "Some Ins and Outs of Indispensability: A Modal-Structural Perspective", in A. Cantini, E. Casari and P. Minari (eds.), Logic in Florence, Kluwer, Dordrecht.

Leng, M., [2002], "What's Wrong With Indispensability? (Or, The Case for Recreational Mathematics)”, Synthese, 131, 2002, pp. 395-417.

- [2010], Mathematics and Reality, Oxford University Press, Oxford-New York.

Liggins, D., [2008], “Quine, Putnam, and the 'Quine-Putnam' indispensability argument", Erkenntnis 68, 2008, pp. 113-27

Maddy, P., [1992], Indispensability and practice, Journal of Philosophy, 89, 1992, 275-289.

- [2005], "Three Forms of Naturalism", in S. Shapiro (ed.), Oxford Handbook of Philosophy of Mathematics and Logic, Oxford University Press, Oxford-New York, pp. 437-60.

— [2007], Second Philosophy, Oxford University Press, Oxford-New York.

Mancosu, P., [2008], "Mathematical Explanation: Why it matters", in P. Mancosu, (ed.), The Philosophy of Mathematical Practice, Oxford University Press, Oxford, 2008. 
Panza, M., Sereni, A. [2013], Plato's Problem. An Historical Introduction to the Philosophy of Mathematics, Palgrave Macmillan, Houndmills, Basinstoke.

Panza, M., Sereni, A. [forthcoming], "The Varieties of the Indispensability Argument", in Synthese, S.I. Indispensability and Explanation, ed. D. Molinini, F. Pataut, A. Sereni.

Parsons, C., [1983], "Quine on the Philosophy of Mathematics", in Parsons, C., Mathematics in Philosophy, Cornell University Press, Ithaca, NY, 1983, also in Hahn L., Schilpp P. (eds.), The Philosophy of W.V. Quine, Open Court, La Salle (IIl), 1986, pp. 369-395.

Paseu, A., [2007], "Scientific Realism", in Leng M., Paseu A., Potter M., (eds.), Mathematical Knowledge, Oxford University Press, Oxford-New York, 2007, pp. 123-149.

Peressini, A., [1997], "Troubles with Indispensability. Applying Pure Mathematics in Physical Theory", Philosophia Mathematica (III), 5, 1997, pp. 210-27.

Peressini, A. [2003], “Critical Study of Mark Colyvan's 'The Indispensability of Mathematics"”, Philosophia Mathematica (3), pp. 208-223.

Pincock, J., [2004], “A Revealing Flaw in Colyvan's Indispensability Argument”, Philosophy of Science, 71, pp.61-79.

Psillos, S., [1999], Scientific Realism: How Science Tracks Truth, Routledge, Oxford.

Putnam, H., [1967], "Mathematics without foundations". The Journal of Philosophy, 64, 1967, pp. 5-22. Reprinted in: Putnam [1975a], pp. 43-59.

— [1971], Philosophy of logic, Harper \& Row, New York, 1971, repr. in Putnam [1975a], ch. 20.

- [1975a], Mathematics, Matter and Method, Philosophical Papers vol. I, Cambridge University Press, Cambridge ( $2^{\text {nd }}$ ed. 1985)

- [1975b], "What is Mathematical Truth?", Historia Mathematica, 2, 1975, pp. 52943, reprinted in Putnam [1975a], ch. 6.

- [1988], "The Greatest Logical Positivist", London Review of Books, 10.8, 1988, pp. 11-13; repr. in H. Putnam, Realism with a Human Face, ed. By J. Conant, Harvard University Press, Cambridge, MA, 1990. 
- [2012] "Indispensability Arguments in the Philosophy of Mathematics", in H. Putnam, Philosophy in an Age of Science, (ed.) M. De Caro and D. Macarthur, Cambridge (MA), Harvard University Press, 2012, 181-201.

Quine, W.V., [1948], "On What There Is", Review of Metaphysics, 2, 1948, pp.21-38, repr. in Quine [1953], ch. 1.

— [1951], “Two dogmas of empiricism”, Philosophical Review, 60, 1951, pp. 20-43, repr. in Quine [1953], ch. 2.

— [1953], From a Logical Point of View, Harper \& Row, New York, (2 ${ }^{\text {nd }}$ ed. 1961)

— [1960], Word and Objects, MIT Press, Cambridge, Mass.

— [1975], "Five Milestones of Empiricism," in Quine [1981b], pp. 67-72.

— [1981a], "Things and Their Place in Theories," in Quine [1981b], pp. 1-23.

- [1981b], Theories and Things, Harvard University Press, Cambridge. Mass.

— [1986], "Reply to Charles Parsons", in Hahn, L., Schlipp, P., (eds), The Philosophy of W.V. Quine, La Salle, Ill., Open Court, 1986.

— [1995], From Stimulus To Science, Cambridge University Press, Cambridge, Mass.

Resnik, M.D., [1995], "Scientific Vs Mathematical Realism: The Indispensability Argument", Philosophia Mathematica (III), 3, 1995, pp.166-174.

— [1997], Mathematics as a Science of Patterns, Clarendon Press, Oxford, 1997.

Shapiro, S. [2005] (ed.), The Oxford Handbook for The Philosophy of Mathematics and Logic, Oxford University Press, Oxford-New York.

Sereni, A. [2013], "Frege, Indispensability, and the Compatibilist Heresy", Philosophia Mathematica, doi: 10.1093/philmat/nkt046

Sober, E., [1993], "Mathematics and indispensability", The Philosophical Review, 102, 1993, pp. 35-57.

Steiner, M., [1978], "Mathematics, Explanation, and Scientific Knowledge”, Noûs, 12, 1978, pp. 17-28.

van Fraassen, B. [1980], The Scientific Image, Oxford University Press, Oxford-New York.

Weir, A.,[2005], "Naturalism Reconsidered”, in Shapiro [2005], pp. 460-482. 